\title{
Nuevo marco para la producción de textos académicos
}

\author{
Grupo Didactext (Didáctica de la escritura)* \\ Universidad Complutense de Madrid (931766)
}

Recibido: 10 de febrero de 2015

Aceptado: 20 de mayo de 2015

\section{RESUMEN}

Este trabajo presenta la reelaboración de un modelo de producción de textos escritos, publicado por el Grupo Didactext en 2003. Se sitúa en un marco sociocognitivo, lingüístico y didáctico, y está concebido desde la interacción de tres dimensiones simbolizadas por círculos concéntricos recurrentes. El primer círculo corresponde al ámbito cultural: las diversas esferas de la praxis humana en las que está inmersa toda actividad de composición escrita. El segundo se refiere a los contextos de producción, de los que forman parte el contexto social, el situacional, el físico, la audiencia y el medio de composición. El tercer círculo corresponde al individuo, en el que se tiene en cuenta el papel de la memoria en la producción de un texto desde el enfoque sociocultural, la motivación, las emociones y las estrategias cognitivas y metacognitivas, dentro de las cuales se conciben seis unidades funcionales que actúan en concurrencia: acceso al conocimiento, planificación, redacción, revisión y reescritura, edición, y presentación oral. La orientación didáctica se interesa por la enseñanza y el aprendizaje de la escritura académica en las aulas, así como por la investigación de la escritura en contextos de educación.

Palabras clave: Proceso de escritura, memoria cultural, estrategias cognitivas y metacognitivas, competencia comunicativa, didáctica de la escritura académica.

\section{A new framework for writing academic texts}

\begin{abstract}
This paper is based on a model for the production of written texts, published by Didactext Group in 2003. It is a re-elaboration of a three-dimensional model: socio-cognitive, linguistic, and didactic, which is graphically symbolized by three reoccurring concentric circles. The first circle corresponds to the cultural environment. That is, each one of the spheres of the human praxis in which the creator of any written text is immersed. The second circle refers to

* El grupo Didactext está compuesto por los siguientes miembros: Silvia AgOSTO RIERA, Teodoro Álvarez Angulo, Salvador Álvaro García, Alejandra Andueza Correa, Marina Arcos ChecA, Zahyra CAMARgo Martínez, Pilar Fernández MARtínez, Jesús Pedro Hilario Silva, Teresa Mateo Girona, Rosario Picó Escalante, Pilar Serrano Almodóvar, y Graciela URIBE Álvarez.
\end{abstract}


the production contexts, which include the social, situational, and physical contexts, as well as the audience and the writing medium. The third circle corresponds to the individual. This last circle looks at the role of memory in writing, including motivation and emotions, sociocultural perspectives, and cognitive and metacognitive strategies. Within these strategies, this paper identifies six functional units: access to knowledge, planning, production of text, revision, rewriting and oral presentation.

Key words: writing process, cultural memory, cognitive and metacognitive strategies, communicative competence, academic writing teaching.

\section{Un nouveau cadre pour la production des textes académiques}

\section{RÉSUMÉ}

Cet article reprend l'élaboration d'un modèle de production de textes écrits, publié par le Groupe Didactext en 2003. Ce modèle est placé dans un cadre sociocognitif, linguistique et didactique et il est conçu à partir de l'interaction de trois dimensions symbolisées par des cercles récursifs. Le premier cercle correspond au domaine culturel, c'est-à-dire, chacune des sphères de la praxis humaine où tout scripteur est engagé ; le deuxième cercle concerne les contextes de production dont fait partie le contexte social, le situationnel, et le physique, ainsi que les auditeurs et les moyens de composition; le troisième cercle correspond à l'individu. On y tient compte du rôle aussi bien de la mémoire dans la production d'un texte dans une approche socioculturelle, que de la motivation, des émotions, et des stratégies cognitives et métacognitives où l'on conçoit six unités fonctionnelles qui agissent en concurrence : accès à la connaissance, planification, production textuelle, révision et réécriture, édition et présentation orale. Cette approche didactique s'intéresse à l'enseignement/apprentissage de l'écriture académique dans la salle de classe et dans des contextes de l'éducation.

Mots clés: Processus d'écriture, mémoire culturelle, stratégies cognitives et métacognitives, compétence communicative, didactique de l'écrit, littéracies universitaires.

SUMARIO: 1. Presentación; 2. Marco teórico y funcionamiento del modelo Didactext; 2.1. Explicación del primer círculo; 2.2. Explicación del segundo círculo; 2.3. Explicación del tercer círculo; 2.4. La enseñanza y el aprendizaje de las estrategias cognitivas y metacognitivas; 3. Hacia un modelo didáctico de la escritura; 4. Conclusiones; 5. Bibliografía.

\section{PRESENTACIÓN}

Esta propuesta reformula el modelo sociocognitivo, pragmalingüístico y didáctico del Grupo Didactext, publicado en 2003. Desde que publicamos la mencionada propuesta, hemos realizado investigaciones (Grupo DiLeMa, 2006-2007; Semillero DiLeMa, 2006; Agosto, 2013; tesis doctorales (Ramírez, 2004; Uribe, 2006; Andueza, 2011; Agosto, 2012), trabajos de fin de máster (Pinilla, 2013; Cardona, 2014; León, 2014; Montes, 2014; Quintero, 2014; Parra, 2015), y experiencias de aula (Agosto y Picó, 2007; Delgado, 2014; Giraldo, 2014; Martínez, 2014; Parra, 2014; Zambrano, 
2014); publicaciones y cursos de formación del profesorado ${ }^{1}$. Todo esto nos ha llevado a profundizar el modo en que comprendemos el fenómeno de la escritura y a introducir modificaciones en el modelo mediante el cual representamos el proceso de producción textual.

El modelo Didactext toma como punto de partida los modelos de escritura, centrados principalmente en teorías cognitivas, sociales y lingüísticas (Álvarez y Ramírez, 2006); y los proyecta a la didáctica de las lenguas, ya que orientan la investigación respecto de cómo se enseña y cómo se aprende a escribir textos académicos (contexto, proceso y texto: géneros discursivos, normas de textualidad y características lingüísticas y textuales de cada género). Desde esta perspectiva de estudio coincidimos con movimientos como Academic Writing, Writing Across the Curriculum, Writing in Disciplines, Writing to Learn, Scaffolding Academic Literacy, que conciben la escritura como una herramienta óptima para el desarrollo del pensamiento y el ingreso a las comunidades discursivas académicas.

En este orden de ideas, el modelo Didactext (2003) establece que la escritura es un proceso que puede analizarse en cuatro fases: el acceso al conocimiento, o activación mental de la información, que posibilita la estimulación de imágenes, de lugares, de acciones, de acontecimientos, desde dentro, que proporciona cierto control sobre contenidos semánticos que, en algún momento, pueden derivar en producción textual; la planificación, o estrategia de organización, que debe estar guiada por la formulación de un objetivo final que oriente el esquema del proceso y busque una estructura, un buen hilo conductor, para dotar de significado propio al texto; la producción textual, que requiere atender tanto a las normas de organización textual interna de orden semántico, como externa, de orden estructural; y la revisión, que desarrolla los pasos evaluativos requeridos hasta la consolidación del texto final.

En esta reformulación del Modelo Didactext incluimos dos nuevas fases en el proceso de escritura: la edición del texto y la presentación oral del mismo. Con ello, ampliamos a seis las fases recursivas que componen el proceso de composición textual, y explicitamos aún más el proceso de redacción y difusión del texto, con el fin de que los escritores sean conscientes de la complejidad que supone la destreza de escribir. Incorporamos también otras modificaciones, que desarrollan didácticamente la fase de acceso al conocimiento, o cómo revisar textos académicos, entre otras.

A continuación, presentamos la descripción del proceso de escritura, así como la explicación de cómo funciona y cuáles son los fundamentos del modelo o teoría de la escritura Didactext.

\footnotetext{
${ }^{1}$ Merece destacarse, a este propósito, el portal RedacText 2.0: Guía online para ayudar a redactar textos académicos (www.redactext.es), diseñado, validado y experimentado por el Grupo Didactext.
} 


\section{MARCO TEÓRICO Y FUNCIONAMIENTO DEL MODELO DIDACTEXT}

A partir de los años 70, la investigación acerca de la composición escrita ha generado diversos modelos que enfatizan, ya sea el producto, textos de diversas características y finalidades, ya sea los procesos que se ponen en juego para elaborarlos y producirlos. Nuestra propuesta reelabora el modelo presentado por Hayes en 1996 para la producción de un texto escrito e incorpora algunos aspectos que el anterior modelo no contempla, al menos de forma explícita, ya que se centra predominantemente en los aspectos cognitivos de la producción textual. Elegimos este modelo por ser el más seguido, juntamente con el de Bereiter y Scardamalia (1987), en la literatura especializada. En consonancia con estos autores, concebimos la creación de un texto como un proceso complejo en el que intervienen de manera interrelacionada factores culturales, sociales, emotivos o afectivos, cognitivos, físicos (viso-motores), discursivos, semánticos, pragmáticos y verbales.

Las modificaciones propuestas al modelo de Hayes pretenden explicitar los procesos cognitivos y las estrategias o mecanismos que intervienen en la escritura desde la dimensión envolvente de la cultura, concebida a través de las propuestas teóricas de Bajtín (1989), De Beaugrande y Dressler (1997), van Dijk (1980, 1983, 1994), Kristeva (1978), Bruner (1984) y, muy especialmente, desde los planteamientos de la psicología cultural (Wertsch, 1991; Salomon, 1992; Cole, 1999; Pozo, 2001; entre otros). Este último autor considera necesario $(2001,203)$ :

Incorporar a la mente humana los sistemas de memoria externa proporcionados por la cultura, que no sólo amplifican nuestro conocimiento del mundo y de nosotros mismos sino que lo transforman de modo radical e irreversible, al generar nuevas funciones epistémicas, nuevas formas de conocer el mundo y, en definitiva, de cambiarlo.

Todos estos principios nos sitúan dentro de un constructo teórico de corte sociocognitivo, pragmalingüístico y didáctico.

En efecto, la consideración de la cultura y de los contextos específicos en la producción de un texto, por una parte; y la explicación cognitiva de los procesos que intervienen en la composición escrita, por otra, sitúan la propuesta de Didactext en un paradigma sociocognitivo que entiende que los procesos humanos se desenvuelven siempre en un espacio y en un tiempo específicos. La búsqueda de explicaciones integradoras de los fenómenos humanos, en particular de los que se desarrollan en las escuelas, ha contribuido al surgimiento del paradigma ecológico ${ }^{2}$ con el cual coincidimos en la necesidad de explicar la escritura considerando los aspectos culturales y contextuales que la enmarcan. El desarrollo de la propuesta resalta la importancia de

\footnotetext{
${ }^{2}$ Frente al análisis individual, como ocurre en el paradigma cognitivo, se privilegia el estudio del escenario de la conducta escolar y social; se subraya la interacción entre el individuo y el ambiente y se potencia la investigación de los contextos en los que se desarrollan las personas.
} 
los componentes cognitivos y su estrecha relación con los factores culturales y sociales, mientras que el enfoque didáctico de nuestro modelo de producción de textos propugna una perspectiva de intervención, y no solo de observación, en los procesos de enseñanza y aprendizaje, pues se orienta a la transformación y a la mejora de la práctica, lo cual exige elaborar respuestas a las cuestiones o problemas surgidos de la interacción entre las necesidades y las propuestas didácticas concretas.

De hecho, la especificidad de la didáctica consiste en reflexionar para actuar adecuadamente respecto a la enseñanza y el aprendizaje sistemáticos; es decir, en relación con el desarrollo de competencias generales o específicas (comunicativas). Por eso el aula se convierte en el punto de partida, el lugar de experimentación y el punto de llegada de la investigación científica de la didáctica de la escritura.

El siguiente diagrama diseñado en círculos concéntricos dinámicos, tal como señalan las flechas, cuyos elementos influyen de manera sucesiva, alternada y permanente en la producción de un texto escrito, ilustra nuestra comprensión de los factores y dimensiones que intervienen en esta producción. Las líneas discontinuas indican la permeabilidad de los círculos; es decir, la posibilidad de que los elementos y aspectos de los círculos externos influyan en los internos y los de estos en los externos (procesos que van de lo general a lo particular y viceversa). En la circularidad también se reflejan movimientos que van de derecha a izquierda y de izquierda a derecha, sin orden preestablecido o jerarquía direccional alguna.

- Circular y concéntrico (flexible y en movimiento)

-Mutua interdependencia de sus elementos

-Recursivo y no jerárquico

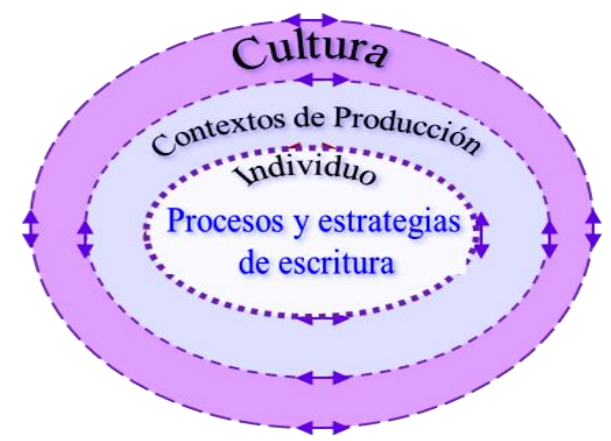

Fig. 1. Características del modelo

\subsection{Explicación del primer círculo}

En el primer círculo de afuera hacia dentro se tiene en cuenta la cultura, llamada obra externa por Bajtín $(1989,81)$, quien lo expresa en los siguientes términos: "La estratificación interna de una lengua nacional en dialectos sociales, de grupos, argots profesionales, lenguajes de género, lenguajes de generaciones, de edades, de corrientes; lenguajes de autoridades, de círculos y modas pasajeras; lenguajes de los días e incluso de las horas; sociopolíticos".

Se trata, por tanto, del elemento marco que envuelve toda producción, y en el que están presentes cada una de las esferas de la praxis humana. 
Cada una de estas esferas genera sus propias formas típicas y relativamente estables para la estructuración de los enunciados, llamados por Bajtín géneros discursivos, considerados como registros sociales o modos de discurso, definidos por el contexto social, la forma de enunciación y el tema. Él profundiza en este aspecto convirtiéndolo en categoría central de la enunciación y de los tipos de texto. Para este teórico, los géneros discursivos se corresponden con la multiforme variedad de esferas de la actividad humana, que dan lugar a tipos estables de enunciados, caracterizados no solo temática y estilísticamente, sino, sobre todo, por su composición o estructuración. Así lo expresa Bajtín $(1979,267)$ :

La voluntad discursiva del hablante se realiza ante todo en la elección de un género discursivo determinado. La elección se define por la especificidad de una esfera discursiva dada, por las consideraciones del sentido del objeto o temáticas, por la situación concreta de la comunicación discursiva, por los participantes de la comunicación, etc. [...]. Nos expresamos únicamente mediante determinados géneros discursivos, es decir, todos nuestros enunciados poseen unas formas típicas para la estructuración de la totalidad, relativamente estables.

En este marco, los textos se muestran, entonces, como el producto de una puesta en funcionamiento, no solo de la materia lingüística, sino también y, sobre todo, de la articulación o integración de esa materia en un contexto histórico, cultural y social. De igual forma están presentes las voces-idea (polifonía) que atraviesan el universo cultural y que esbozan diversos puntos de vista específicos. Bajtín, en síntesis, entiende la cultura como un sistema de diálogos que involucra la representación de $h a$ blas, de estilos, de concepciones concretas, de los cuales el individuo se alimenta (heteroglosia). Asimismo, estas diversas visiones del mundo son concebidas por Kristeva (1978) como ideologemas; es decir, múltiples enunciados que se pueden leer en los distintos niveles de la estructura textual y que lo ubican en el texto de la sociedad y de la cultura. Tanto las tipologías como los géneros concretos son convenciones sociales y constituyen uno de los conocimientos psico-socio-verbales necesarios para los usuarios, que los identifican como apropiados para determinadas metas (Isenberg, 1983; Bronckart, 1996; Rose y Martin, 2012).

En síntesis, este primer círculo reúne, en una amplia dimensión, el ámbito cultural que comprende, entre otros, los ritos, las normas, las creencias, los valores, la diversidad cultural, los sistemas de escritura, la numeración, las representaciones del tiempo, las redes semánticas, las proposiciones, los esquemas, el lenguaje, las normas de textualidad y los principios regulativos (De Beaugrande y Dressler, 1997), las formas y los procesos de escritura (Hayes, 1996), las representaciones, las experiencias históricas e ideologías (van Dijk, 2003; Halliday y Martin, 1993), resultado de convenciones socioculturales adoptadas por un grupo o una colectividad, en momentos diferentes de su historia y con objetivos concretos y con diversas significaciones de 
las que el individuo hace uso e incorpora a su memoria para el desarrollo de su proceso creativo y de su relación con el mundo. A continuación mostramos la representación gráfica de este primer círculo:

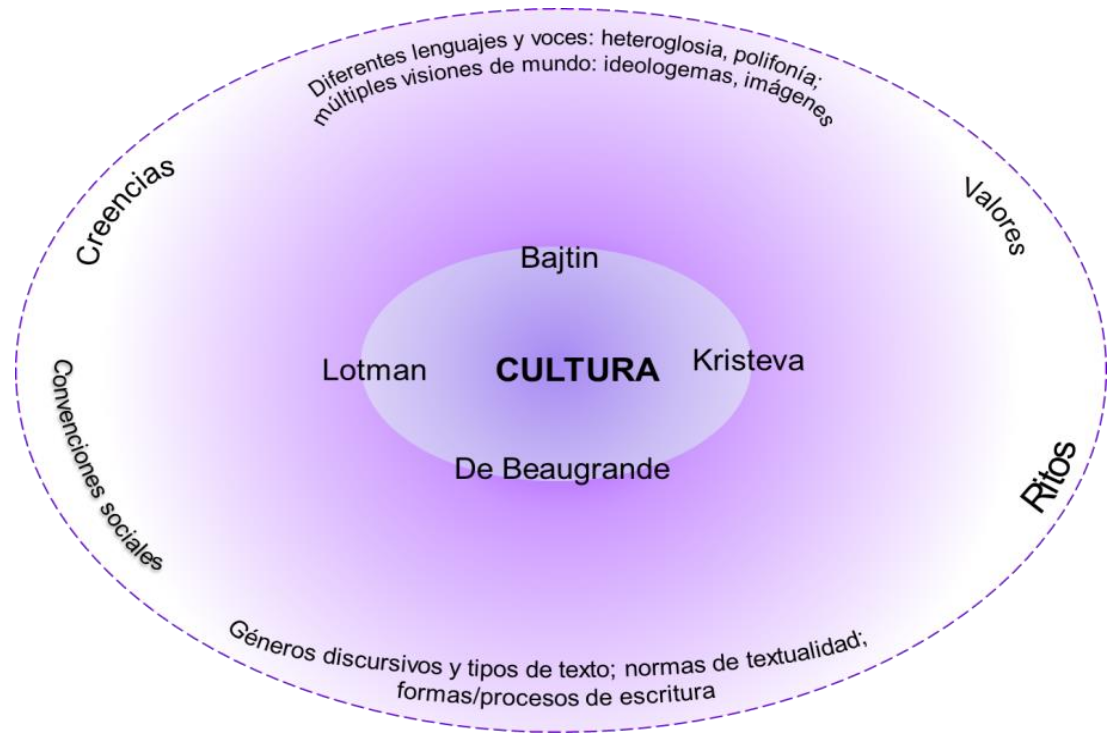

Fig. 2. Primer círculo: Cultura

\subsection{Explicación del segundo círculo}

El segundo círculo delimita los factores externos que influyen en la composición de un texto escrito, o sea, los contextos de producción, que pueden definirse como el conjunto de los parámetros susceptibles de ejercer una influencia en la manera como un texto está o es organizado. O como Hayes propone, conformados por el contexto social (audiencia y colaboradores) y por el medio de composición. En nuestra propuesta estos elementos han sido concebidos de manera más amplia, es decir, pensados desde el término latino contexere, que significa entrelazar o, como lo define Albadalejo (1987, 190): "conjunto de factores temporales, locales, culturales, de tradición literaria, sociales, etc., que constituyen el medio en el que el acto de comunicación lingüística tiene lugar" Para van Dijk (1997b), lo contextual orienta la manera como la información acerca de la situación va a ser enmarcada en el texto; en otros términos, cada cual hace uso de unos determinados esquemas (historia de interacción social, estilo, estructura formal, selección de palabras), según el rol que en ese momento desempeñe, porque, como es conocido, somos partícipes de varios grupos al mismo tiempo. La pertenencia a diferentes grupos, el cambio de interlocutores y la diversidad de entornos ocasionan la gran variedad de géneros discursivos que median la comunicación humana (Bazerman, 2009; Bajtin, 1979; Bronckart, 1996). 
En el contexto social están comprendidos los aspectos políticos, educativos, jurídicos, laborales, económico-comerciales, familiares, las relaciones cotidianas, el ocio, concebidos todos ellos no como entidades independientes sino como diversos momentos dentro de un único proceso, cuyos límites no son claros y estáticos sino ambiguos y dinámicos.

En el contexto situacional se tienen en cuenta varios niveles: el entorno geográfico (mar, montaña...), su arquitectura (ciudad, periferia...), y el entorno más inmediato o el lugar donde se desarrolla la actividad; factores que afectan a la cultura de cada grupo humano. Según González y Aguilar $(2003,100)$ :

Un grupo humano situado en una geografía concreta tiene que enfrentarse a ella, aprender a sobrevivir en ella. Este aprendizaje para la supervivencia se realiza a través del trabajo que se desarrolla y que, a su vez, configura las distintas organizaciones sociales. Para realizar el trabajo el hombre no sólo crea una tecnología sino también una organización económica y política, que va formando parte de su medio ambiente. La cultura responde y se configura condicionada por el medio ambiente, el trabajo y la organización social, de ellos se derivan la visión del mundo, el universo simbólico, los valores, la identidad e, incluso, la autoestima.

En relación con la audiencia (receptores) conviene tener en cuenta la edad, el género, la profesión, el estatus, la distancia social, las capacidades cognitivas, las motivaciones, los intereses, los estados de ánimo, las actitudes; además, se considera de vital importancia la postura de los colaboradores y también la de los detractores, quienes ponen en tela de juicio el contenido, la estructura y la funcionalidad del texto.

El contexto físico se refiere al lugar (espacio físico) y al medio de composición utilizado para la ejecución de la tarea de escritura (redes sociales, lápiz, etc.), que depende, según Pozo (2001), de los artefactos culturales que la sociedad, en la que está inmersa cada persona, emplea como sistemas externos de memoria y que, de hecho, dan forma, se incorporan a los propios sistemas de la memoria humana. En este mismo sentido González y Aguilar afirman que las relaciones con el medio físico y la organización social forjan las creencias, los prejuicios, los artefactos que se emplean y que los grupos humanos y las personas que los constituyen, como entes vivos que son, van cambiando a través de la interacción con su medio y la relación o confrontación con otras culturas. En el siguiente gráfico, se encuentra la representación de lo expuesto: 


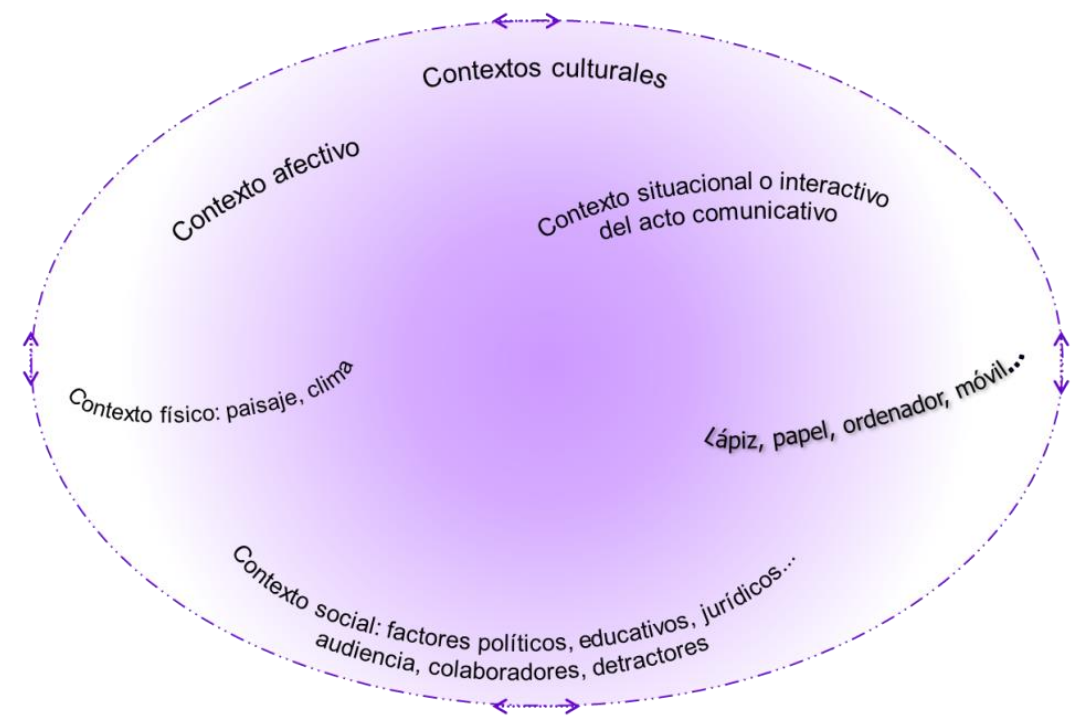

Fig. 3. Segundo círculo: Contextos de producción

\subsection{Explicación del tercer círculo}

Este círculo considera al individuo productor de textos escritos, o, como dice Habermas (1992), constructor de sentidos y productor de historia. Está dividido, por razones didácticas que buscan clarificar los factores que intervienen en el proceso de escritura, en tres dimensiones que se interrelacionan: memoria, motivación-emociones y estrategias cognitivas y metacognitivas:

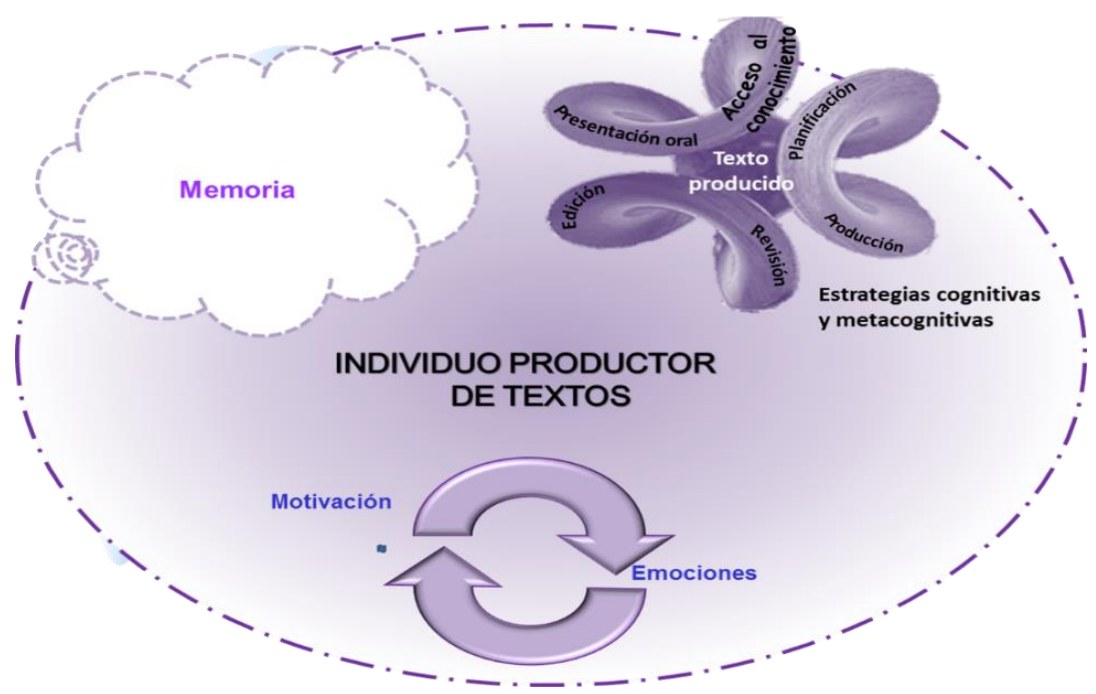

Fig. 4. Tercer círculo: Individuo 
Nuestro modelo postula que la escritura es un proceso que se vincula estrechamente con la lectura y que quien escribe no está situado pasivamente en su medio, sino que, siguiendo a Lotman (1979), "lee" los textos de su cultura y crea otros a partir de ella. Concebimos, entonces, la lectura en un sentido amplio, es decir, también como la lectura de arte, de religión, de vida social, de costumbres, de actuar de las personas; en síntesis, de todas las expresiones que contiene y permite la cultura. En coherencia con los referentes teóricos presentados, y en particular con el encuadre cultural de los procesos de escritura, siempre situados en una cultura y en contextos específicos, entendemos que la producción escrita se desarrolla en estrecha y necesaria relación con la lectura. Ahora, explicaremos cada una de las dimensiones enunciadas con anterioridad:

La primera dimensión de este tercer círculo corresponde a la memoria, estudiada desde la postura del modelo de memoria cultural (la mente como un sistema cultural o colectivo) (Lave y Wenger, 1991; Wertsch, 1991; Salomon, 1992; Wertsch, Del Río, Álvarez, 1995; Pozo, 2001). Según este modelo, frente al carácter individual del sujeto de la psicología cognitiva, se considera que las representaciones mentales se producen y se activan con una mediación cultural, de tal modo que no serían solo representaciones mentales individuales, sino, ante todo, representaciones colectivas (Lave y Wenger, 1991; Salomon, 1992). Para Wertsch (1991), el sujeto de la psicología de la memoria no puede concebirse, como ha sido tradición, como un ser independiente de la sociedad, ya que, además del análisis intrapsicológico (procesos mentales complejos individuales), debe darse otro interpsicológico (interacciones entre personas).

En este orden de ideas, el enfoque sociocultural otorga importancia a la acción mediada en un contexto; al uso del método genético que incluye los niveles, histórico, ontogenético y microgenético de análisis; a la observación de los sucesos de la vida cotidiana. Ello debido a que la mente se construye en relación con el contexto y a que los sujetos son co-autores de su propio desarrollo. Cole $(1999,103)$ considera los siguientes presupuestos como características principales de este enfoque cultural:

- Subraya la acción mediada en un contexto.

- Trata de fundamentar su análisis en acontecimientos de la vida diaria.

- Supone que la mente surge en la actividad mediada conjunta de las personas. La mente es, pues, en un sentido importante, "co-construida" y distribuida.

- Supone que los individuos son agentes activos en su propio desarrollo, pero no actúan en entornos enteramente de su propia elección.

- Rechaza la ciencia explicativa causa-efecto y estímulo-respuesta en favor de una ciencia que haga hincapié en la naturaleza emergente de la mente en actividad y que reconozca un papel central para la interpretación en su marco explicativo. 
Uno de los problemas de la mente humana es, según los psicólogos culturales, el desfase entre el "equipamiento cognitivo de serie" 3 que trae cada individuo y el mundo saturado de información en el que vivimos, que exige cambios de visión muy difíciles de lograr, aun con intervención de la instrucción, ya que el mundo social influye en el individuo no solo por la intervención de las personas que persuaden, enseñan y forman, sino por las prácticas (rutinas, esquemas, juegos, rituales), y por los objetos sociales (palabras, mapas, aparatos de sonido).

Desde este enfoque, la integración entre el modelo cognitivo y el sociocultural, aunque difícil, será posible en la medida en que se acepte que el lenguaje ayuda a reprogramar el cerebro, reestructura la mente humana y los artefactos culturales que actúan como prótesis cognitivas que apoyan o amplían el funcionamiento de la mente, de la misma forma como unos anteojos amplifican la visión, sin alterar su naturaleza. El propósito, asevera Pozo $(2001,80)$ :

No es sólo que los artefactos culturales modifiquen o reestructuren los sistemas cognitivos sino que, a su vez, cada persona, cada sistema cognitivo que incorpora o interioriza esos sistemas culturales de representación, debe reconstruirlos y, en esa medida, adaptarlos a las propias restricciones impuestas por el equipamiento cognitivo de serie de la mente humana.

Es decir, cada individuo tiene diferentes formas de representación externa y esto genera nuevos usos y nuevos sistemas de representación interna.

La segunda dimensión de este tercer círculo explicita la presencia de las motivaciones y las emociones en la tarea de escribir, ya que nuestros estados de ánimo y los procesos mentales implícitos tienen necesariamente un componente emocional, y no únicamente en relación con el mundo social, sino también con el físico. Entendemos así la motivación como un proceso o serie de procesos que, de algún modo, inician, rigen, mantienen $\mathrm{y}$, finalmente, definen una secuencia de conducta dirigida a una meta; y la emoción como el conjunto de mecanismos que establecen las metas prioritarias de un sujeto; por ello tienen un origen multicausal, presentan formas diversas de expresión y cumplen funciones determinadas.

Los procesos motivacionales y los procesos emocionales comparten entre sí los siguientes aspectos: son procesos funcionales que permiten a los sujetos la adaptación y la respuesta a un ambiente determinado; sin embargo, A. Puente Ferreras (1998) considera que estas relaciones no siempre se manifiestan de forma lineal; en lugar de

\footnotetext{
${ }^{3}$ Concepto desarrollado por varios psicólogos, entre ellos Pozo y Gómez Crespo (1998), para referirse a las restricciones cognitivas que el propio cuerpo y la mente humana se imponen frente al conocimiento del mundo. Se trata del equipamiento básico con el que todos estamos dotados.
} 
eso, la influencia de las emociones puede estar mediatizada por diferentes mecanismos que impliquen efectos acumulativos o contrapuestos, lo que hace difícil predecir los efectos en la ejecución de una tarea. Tanto la motivación como las emociones mantienen relaciones estrechas con otros procesos psicológicos, como la percepción, la atención, la memoria, y el aprendizaje. Si nos referimos al contexto educativo, parece evidente que las actitudes, creencias, percepciones, expectativas y representaciones que tenga el sujeto de sí mismo, de la tarea, y de los objetivos y metas que pretenda alcanzar, constituyen factores de primer orden que guían y dirigen su conducta en el ámbito académico.

En la actualidad existe un creciente interés en considerar de forma integrada tanto los componentes cognitivos como los afectivo-motivacionales que influyen en el aprendizaje, porque para aprender es imprescindible "poder" realizarlo, lo cual hace referencia a las capacidades, los conocimientos, las estrategias, y las destrezas necesarias; pero, además, es importante "querer" hacerlo, tener la disposición, la intención, la motivación y la persistencia suficientes. Por otra parte, el aprendizaje no queda, en absoluto, reducido exclusivamente al plano cognitivo, en sentido estricto, sino que, como ya hemos señalado, es afectado también por otros aspectos motivacionales como las intenciones, los objetivos o las metas, las percepciones, las actitudes y las creencias que tiene el sujeto que aprende, lo que subraya la enorme interrelación que mantienen el ámbito cognitivo y el afectivo-motivacional.

Pintrich (1989) argumenta que las variables personales afectivo-motivacionales (autoconcepto, creencias, actitudes, horizonte de expectativas, metas de aprendizaje y emociones) constituyen los elementos clave de toda situación educativa, cuya interrelación determinará, en gran medida, la motivación. En síntesis, los procesos motivacionales tienen que ver con un conjunto de relaciones entre variables tales como el horizonte de expectativas, los objetivos o las metas, la afectividad, la creatividad, el cálculo entre el coste y el beneficio, las creencias y actitudes, que explican la activación, dirección y persistencia de la conducta de una persona, y que comentamos brevemente a continuación.

El horizonte de expectativas hace referencia a las ideologías, creencias, actitudes y perspectivas que tiene un sujeto para realizar una determinada tarea. Dentro del horizonte de expectativas interviene el autoconcepto, que es el resultado de un proceso de análisis, valoración e integración de la información derivada de la propia experiencia y de la retroalimentación de los demás (compañeros, padres, profesores). Una de las funciones más importantes del autoconcepto es la de regular la conducta mediante un proceso de autoevaluación o autoconciencia. Bandura (1987) afirma que el sujeto anticipa el resultado de su conducta, a partir de las valoraciones que hace de sus capacidades; es decir, genera expectativas, bien de éxito, bien de fracaso, que repercutirán sobre su motivación y rendimiento.

Las metas u objetivos de aprendizaje se definen como el propósito o compromiso con la tarea. Este componente indica las metas del sujeto y sus creencias sobre la importancia e interés de la misma. El tipo de meta establece los parámetros mediante 
los cuales los sujetos registran los logros. Hay dos tipos de metas: de rendimiento y de aprendizaje. Las primeras se centran en el yo, en la demostración de las competencias frente a otros; y las segundas, en el desarrollo de competencias para el logro de la tarea. Las metas que se eligen dan lugar a diferentes modos de afrontar las tareas académicas y a distintos patrones motivacionales.

La afectividad se refiere a las reacciones emotivas y afectivas ante la tarea. Es posible distinguir entre las emociones dirigidas al sujeto mismo y las dirigidas hacia los demás. Las emociones dependen de las cogniciones y también de los sentimientos de autoestima, de autovalía y de competencia.

La creatividad es otro componente importante de los procesos motivacionales. Según Amabile (1988), aunque la motivación extrínseca en ausencia de la intrínseca puede debilitar la creatividad, la combinación de ambas la intensifica de manera notoria. La creatividad se hace también indispensable en los procesos cognitivos habituales y permite el planteamiento de otras maneras de mirar, de pensar y de hacer.

El coste y el beneficio en la tarea de escritura es muy difícil de calcular, porque quien se inicia tiene que entregar mucho más de lo que espera recibir, pero seguramente solo el logro de un sentimiento de realización procedente de haber encontrado el proceso y las formas de la composición escrita se tiene en cuenta como beneficio.

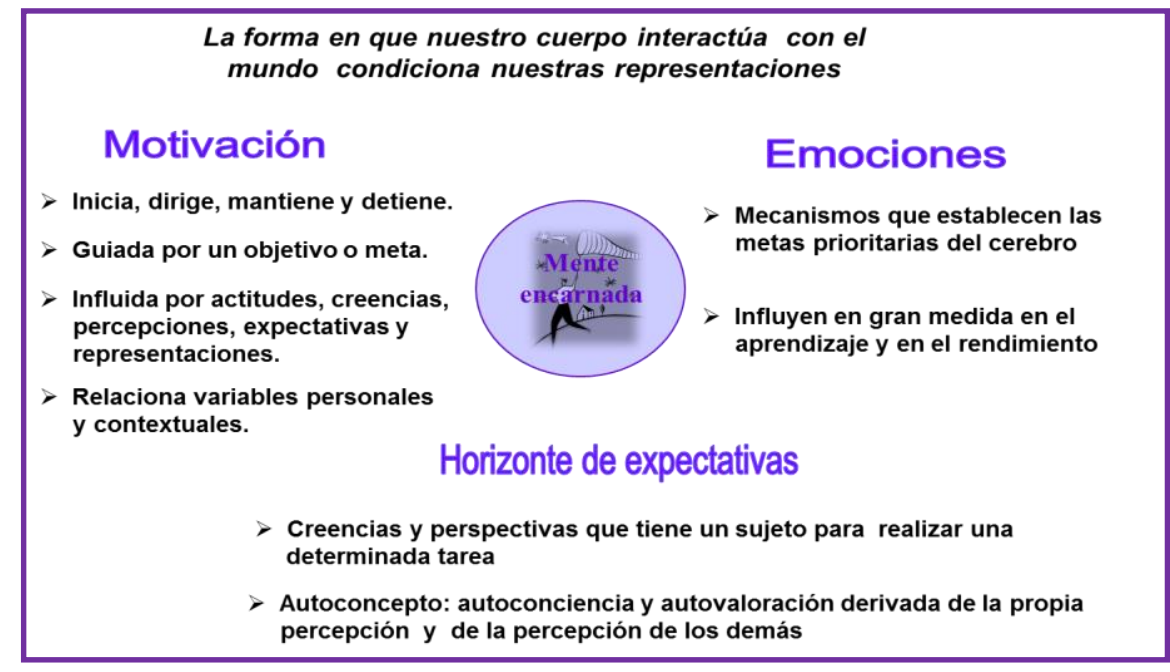

Fig. 5. Dimensión Motivación/Emociones

La tercera dimensión de este tercer círculo hace referencia a los llamados por Hayes procesos cognitivos, que redenominamos estrategias cognitivas y metacognitivas, porque queremos centrarnos en aquellas estrategias que intervienen en el proceso de producción textual propiamente dicho. Entendemos que el término estrategia añade los rasgos "consciente" e "intencionado," que los procesos cognitivos, considerados de forma general, no necesariamente suponen. 
En los estudios pedagógicos y psicológicos, el término estrategia (del gr, Strateguía, arte de dirigir las operaciones militares) ha pasado también a significar la planificación conjunta de las directrices que se han de seguir en cada una de las fases de un proceso; así entendida, la estrategia guarda relación con los objetivos que se pretende lograr y con su determinación. Bruner (2001) entiende por estrategia un modelo de decisiones en la adquisición, retención y utilización de información que sirve para obtener ciertos objetivos, para asegurar la presencia de determinadas formas de resultado y la exclusión de otras. Por su parte, J. Mayor, A. Suengas y J. González (1995) consideran que la programación consciente de estrategias de aprendizaje, de memoria, de solución de problemas, de toma de decisiones, hará que se amplíe la capacidad y la eficacia del aprendizaje. La mayoría de teóricos conciben las estrategias (tácticas, planes) como procedimientos que se aplican de modo controlado dentro de un plan diseñado deliberadamente, con el fin de conseguir una meta fijada.

La estrategia pone en juego habilidades (técnicas, destrezas, hábitos) previamente aprendidas. Fitts (1964) y J. Anderson y J. R. Anderson (1982) sostienen que las habilidades pasan por tres etapas características en su asimilación por parte de los sujetos: una primera etapa, cognitiva, en la que se trabaja a partir de las instrucciones o un ejemplo de cómo debe realizarse la tarea; una segunda etapa, asociativa, en la que la habilidad hace una transición de un uso lento y deliberado del conocimiento a una representación más directa de lo que se debe hacer; y una tercera etapa llamada autónoma, porque es la que genera las rutinas de acción automatizadas. Las habilidades pueden ser motoras, cognitivas o combinadas.

La identificación de habilidades con técnicas no es aceptada por toda la comunidad de investigadores. Por ejemplo, para Justicia et al. (2000), las habilidades cognitivas son capacidades dispuestas para usar el pensamiento y el razonamiento abstracto, que se desarrollan por medio de técnicas hasta alcanzar grados crecientes de pericia. Para Harré y Lamb (1986/1990) las habilidades (skills) son capacidades para desempeñar determinadas tareas o alcanzar metas específicas. Muchas habilidades pueden ser adquiridas, a veces después de un largo periodo de adiestramiento y de práctica. Los atributos que definen una habilidad son su eficacia y su flexibilidad. La eficacia significa que el acto en cuestión puede ejecutarse con rapidez, exactitud y economía, lo cual confiere mayor validez a su ejecución. La flexibilidad indica la diversidad de procesos y mecanismos que deben sustentarla.

En la elaboración de nuestra propuesta se han considerado, además, las aportaciones de otros autores con el propósito de esbozar una visión integrada de las estrategias que intervienen en el proceso de composición escrita, entre ellos Monereo (1990), para quien las estrategias cognitivas son susceptibles de ser enseñadas y actúan sobre un problema o tarea específica, con el objeto de facilitar su adquisición por el sistema cognitivo. Weinstein y Mayer (1986) las desglosan en estrategias de repetición, de elaboración y de organización. Gaskins y Elliot (1999) entienden que hay dos categorías de estrategias: cognitivas, relacionadas con el logro de metas y metacognitivas, 
aquellas que controlan el proceso en sus avances, interferencias o retrocesos. En nuestro modelo entenderemos por estrategia un proceso cognitivo y metacognitivo específico que busca la consecución de objetivos, a través de una planificación consciente e intencionada. Dicho de otra manera, tenemos en cuenta las características más universales de la estrategia: ser procesual, orientada hacia una meta u objetivo, controlable, deliberada y dependiente de las particularidades de la persona que la pone en ejercicio, y educable y flexible para hacer más eficaz el aprendizaje.

El concepto de metacognición es introducido por Flavell (1979) para dar cuenta de la comprensión y la percepción de uno mismo y de los propios procesos cognitivos, o de cualquier aspecto relacionado con ellos. Las estrategias metacognitivas preparan a los alumnos para tener el control de las variables: tarea, persona, estrategia y ambiente. A continuación citamos algunas de las estrategias cognitivas y metacognitivas presentadas por Gaskins y Elliot (1999, 97-109):

\section{Estrategias cognitivas}

1. Estrategias para alcanzar el sentido y recordarlo:

-Acceder al conocimiento previo

-Predecir, formular hipótesis y/o plantear objetivos

-Comparar

-Crear imágenes mentales

-Hacer inferencias

-Generar preguntas y pedir aclaraciones

-Seleccionar ideas importantes

-Transferir o aplicar conceptos a nuevas situaciones

2. Estrategias para la producción de conocimiento:

-Reconocer, identificar o admitir un problema

-Definir o analizar el problema

-Decidir sobre un plan

-Poner en funcionamiento el plan

-Evaluar tanto el avance hacia la solución como la solución

3. Estrategias para la composición

-Acceder al conocimiento

-Planificar

-Hacer un borrador

-Revisar

Estrategias metacognitivas:

1. Estrategias para dominar variables de tarea

1.1. Analizar la tarea

-Identificar la tarea

-Establecer una meta

-Expresar la comprensión de la tarea

-Comprobar la propia comprensión de la tarea discutiéndola con otros

-Activar conocimientos previos 
-Organizar, categorizar, representar gráficamente ideas del propio conocimiento previo

1.2. Diseñar estrategias adecuadas vinculadas a la tarea

-Determinar y formular los pasos necesarios para cumplir la tarea

-Diseñar un programa para completar la tarea

-Usar estrategias compensatorias como, por ejemplo: leer un libro, ver un vídeo o una película sobre el tópico de la tarea o tener una discusión sobre el tema con alguien que posea más conocimientos al respecto

2. Estrategias para dominar variables personales

-Analizar variables personales tales como ideologías, creencias, actitudes, motivaciones

-Seleccionar estrategias personales adecuadas

3. Dominio de variables de estrategias

-Evaluar y seleccionar las estrategias cognitivas adecuadas

4. Estrategias para dominar variables ambientales relacionadas con el entorno

-Analizar factores ambientales

-Seleccionar estrategias adecuadas en relación con el entorno.

\subsection{La enseñanza y el aprendizaje de las estrategias cognitivas y meta- cognitivas}

La complejidad del proceso de escritura exige a los escritores aplicar múltiples estrategias cognitivas y metacognitivas para lo cual requieren conocimientos específicos respecto de cómo escribir (dimensión retórica del texto) y de qué escribir (dimensión proposicional del texto).

La investigación en psicología cognitiva suele distinguir tres fases de la producción textual -planificación, escritura y revisión- a lo largo de las cuales los escritores expertos aplican estas estrategias. Dichas fases son recursivas, es decir, se repiten e intercalan durante el proceso de escritura y son esenciales para la construcción del sentido del texto (Bereiter y Scardamalia, 1987; Hayes, 1996; Hayes y Gradwohl (1996); Somners (2007); en otras palabras, por ejemplo, en la planificación, el escritor genera y selecciona las ideas que se van a transmitir, al escribir surgen nuevas ideas que implican revisar la planificación, modificarla y continuar con el proceso de textualización, en medio del cual el escritor verifica si lo que está escribiendo se ajusta al propósito, a la audiencia, si constituye una unidad de sentido, introduce transformaciones, etc., ya que el proceso de escritura se constituye en una resolución constante de problemas.

Con todo, las estrategias cognitivas y metacognitivas implicadas en cada una de estas fases no se desarrollan de manera espontánea, al menos en la gran mayoría de los escritores; por el contrario, su adquisición requiere de una instrucción sistemática que, por una parte, explicite al estudiante cuáles son esas estrategias y, por otra, ofrezca oportunidades para aprender a ponerlas en práctica y llegar a internalizarlas.

En vista de lo anterior, este modelo, de orientación didáctica, se plantea como desafío proponer un modo de enseñar y aprender esas estrategias a lo largo de la 
educación escolar y superior. Este planteamiento parte de la base de que cuando los escritores todavía no han alcanzado la experticia, su memoria de trabajo es limitada $\mathrm{y}$, por lo tanto, su capacidad de gestionar los conocimientos y las habilidades necesarias para resolver la tarea de escribir un texto complejo también lo es (Kintsch, 2004).

Por ello, proponemos una manera de concebir la relación entre las fases de la escritura y las estrategias cognitivas y metacognitivas que deben ponerse en juego durante la producción textual. Esta estructuración es, por supuesto, una propuesta organizadora que no indica un orden secuencial estricto: muchas estrategias del acceso al conocimiento se retoman más adelante en el proceso de producción textual: cada fase plantea un producto que a la vez es revisado y modificado conforme avanza el proceso de escritura. En este sentido, proponemos una aproximación más analítica al proceso de producción textual que permita separar sus partes constituyentes y enseñarlas de manera sistemática de modo que el escritor vaya internalizándolas progresivamente.

Esta manera de proceder ayuda a regular la tensión cognitiva que supone gestionar una gran cantidad de estrategias, habilidades y conocimientos de manera simultánea y permite que el escritor inexperto vaya resolviendo de manera más o menos articulada los diversos problemas que enfrenta durante la escritura de su texto. En otras palabras, lo que planteamos es articular una propuesta operativa para el aula.

Ya desde el principio se ha insistido en la necesaria recursividad del proceso de composición; por lo tanto, la elección de una propuesta de trabajo que aparece en forma de lista no significa que se deba proceder en ese orden; todo lo contrario, si se acepta que la producción escrita es una actividad organizada de resolución de problemas con objetivos determinados, que se produce a lo largo del tiempo y es socialmente construida (recibe el apoyo y los aportes de muchos interlocutores), se da por hecho que la escritura se manifiesta a través de un sujeto que avanza y retrocede, que revisa, que dialoga, que produce, que consulta, que borra y vuelve a escribir, antes de dar por terminado un texto.

Sin desconocer la importancia de las otras estrategias cognitivas presentadas por Gaskins y Elliot, citadas anteriormente, consideramos de mayor interés, para el objetivo de dar razón sobre el proceso de escribir, las llamadas estrategias para la composición, que se reformulan en el siguiente esquema de Estrategias cognitivas y metacognitivas del proceso de producción de textos:

\begin{tabular}{|c|l|l|}
\hline Fases & \multicolumn{1}{|c|}{ Estrategias cognitivas } & \multicolumn{1}{|c|}{$\begin{array}{c}\text { Estrategias } \\
\text { metacognitivas }\end{array}$} \\
\hline $\begin{array}{c}\text { Acceso al co- } \\
\text { nocimiento } \\
\text { (Leer el } \\
\text { mundo) }\end{array}$ & $\begin{array}{l}\text { Buscar ideas para tópicos. } \\
\text { Rastrear información en la memoria, en conoci- } \\
\text { mientos previos y en fuentes documentales. }\end{array}$ & $\begin{array}{l}\text { Reflexionar sobre el } \\
\text { proceso de escritura. } \\
\text { Examinar factores am- } \\
\text { identificar al público y definir la intención. } \\
\text { Recordar planes, modelos, guías para redactar, } \\
\text { géneros y tipos textuales. }\end{array}$ \\
\hline
\end{tabular}




\begin{tabular}{|c|c|c|}
\hline $\begin{array}{l}\text { Producto: } \\
\text { Elaboración } \\
\text { de notas }\end{array}$ & $\begin{array}{l}\text { Hacer inferencias para predecir resultados o } \\
\text { completar información. }\end{array}$ & $\begin{array}{l}\text { Evaluar estrategias po- } \\
\text { sibles para adquirir sen- } \\
\text { tido y recordarlo. } \\
\text { Analizar variables per- } \\
\text { sonales. }\end{array}$ \\
\hline $\begin{array}{c}\text { Planificación } \\
\text { (Leer para sa- } \\
\text { ber) } \\
\text { Producto: es- } \\
\text { quemas y re- } \\
\text { súmenes }\end{array}$ & $\begin{array}{l}\text { Seleccionar la información necesaria en función } \\
\text { del tema, la intención y el público. } \\
\text { Formular objetivos. } \\
\text { Clasificar, integrar, generalizar y jerarquizar la } \\
\text { información. } \\
\text { Elaborar esquemas mentales y resúmenes. } \\
\text { Manifestar metas de proceso. }\end{array}$ & $\begin{array}{l}\text { Diseñar el plan (prever } \\
\text { y ordenar las acciones). } \\
\text { Seleccionar estrategias } \\
\text { personales adecuadas. } \\
\text { Observar cómo está } \\
\text { funcionando el plan. } \\
\text { Buscar estrategias ade- } \\
\text { cuadas en relación con } \\
\text { el entorno. } \\
\text { Revisar, verificar o co- } \\
\text { rregir las estrategias. }\end{array}$ \\
\hline $\begin{array}{l}\text { Producto: bo- } \\
\text { rradores o } \\
\text { textos inter- } \\
\quad \text { medios }\end{array}$ & $\begin{array}{l}\text { Organizar según: géneros discursivos; tipos tex- } \\
\text { tuales; normas de textualidad (cohesión, coheren- } \\
\text { cia, intencionalidad, aceptabilidad, situacionali- } \\
\text { dad, informatividad, intertextualidad); mecanis- } \\
\text { mos de organización textual; marcas de enuncia- } \\
\text { ción, adecuación; voces del texto, cortesía, mo- } \\
\text { dalización, deixis, estilo y creatividad. } \\
\text { Desarrollar el esquema estableciendo relaciones } \\
\text { entre ideas y / o proposiciones; creando analo- } \\
\text { gías; haciendo inferencias; buscando ejemplos y } \\
\text { contraejemplos. } \\
\text { Redactar teniendo en cuenta el registro ade- } \\
\text { cuado según el tema, la intención y el público } \\
\text { destinatario. } \\
\text { Elaborar borradores o textos intermedios. }\end{array}$ & $\begin{array}{l}\text { Supervisar el plan y las } \\
\text { estrategias relacionadas } \\
\text { con la tarea, lo personal } \\
\text { y el ambiente. }\end{array}$ \\
\hline $\begin{array}{l}\text { Revisión y } \\
\text { reescritura } \\
\text { (Leer para cri- } \\
\text { ticar y revi- } \\
\text { sar) } \\
\text { Producto: } \\
\text { texto produ- } \\
\text { cido }\end{array}$ & $\begin{array}{l}\text { Leer para identificar y resolver problemas tex- } \\
\text { tuales (faltas orto-tipográficas, faltas gramatica- } \\
\text { les, ambigüedades y problemas de referencia, } \\
\text { defectos lógicos e incongruencias, errores de he- } \\
\text { cho y transgresiones de esquemas, errores de es- } \\
\text { tructura del texto, incoherencia, desorganiza- } \\
\text { ción, complejidad o tono inadecuados) mediante } \\
\text { la comparación, el diagnóstico y la supresión, } \\
\text { adjunción, reformulación, desplazamiento de } \\
\text { palabras, proposiciones y párrafos. } \\
\text { Leer para identificar y resolver problemas rela- } \\
\text { cionados con el tema, la intención y el público. }\end{array}$ & $\begin{array}{l}\text { Revisar, verificar o co- } \\
\text { rregir la producción es- } \\
\text { crita. }\end{array}$ \\
\hline Edición & $\begin{array}{l}\text { Preparar el texto para difundirlo. } \\
\text { Adecuar gráficamente el texto a la intención para } \\
\text { la que se ha creado. }\end{array}$ & \\
\hline
\end{tabular}




\begin{tabular}{|c|c|c|}
\hline $\begin{array}{c}\text { (Leer para pu- } \\
\text { blicar) }\end{array}$ & $\begin{array}{l}\text { Observar, establecer y organizar tipo de letra, ta- } \\
\text { maño, ilustraciones, puntuación, color del texto } \\
\text { final. } \\
\text { Determinar el diseño y la distribución del escrito } \\
\text { según el tipo de texto y género. }\end{array}$ & $\begin{array}{l}\text { Reflexionar sobre cómo } \\
\text { transmitir fidedigna- } \\
\text { mente la intención for- } \\
\text { mulada al inicio en el } \\
\text { nuevo marco de difu- } \\
\text { sión. }\end{array}$ \\
\hline $\begin{array}{c}\text { Presentación } \\
\text { oral } \\
\text { (Leer para en- } \\
\text { señar) }\end{array}$ & $\begin{array}{l}\text { Extraer ideas principales mediante las macrorre- } \\
\text { glas de T. van Dijk (supresión, generalización y } \\
\text { construcción). } \\
\text { Elaborar diapositivas en power point o cualquier } \\
\text { otra forma audiovisual con esquemas, videos, } \\
\text { mapas mentales que sirvan como recursos nemo- } \\
\text { técnicos al orador } \\
\text { Dominar un lenguaje oral formal }\end{array}$ & $\begin{array}{l}\text { Buscar estrategias para } \\
\text { transmitir la informa- } \\
\text { ción oralmente, con- } \\
\text { forme a las característi- } \\
\text { cas del registro oral for- } \\
\text { mal. } \\
\text { Desarrollar reglas ne- } \\
\text { motécnicas para memo- } \\
\text { rizar el discurso. }\end{array}$ \\
\hline
\end{tabular}

Fig. 6. Estrategias cognitivas y metacognitivas del proceso de redacción de textos

La aplicación de las estrategias cognitivas y metacognitivas determinadas en el cuadro anterior se distribuye en fases recursivas que van conformando el proceso de escritura del texto. En la siguiente figura mostramos la idea de recursividad, consistente en hacer ver la interrelación de las distintas fases o etapas que conforman la composición de todo texto. No se trata, por tanto, de una concepción lineal de la producción del texto, sino que, a medida que este avanza en su composición, se van interrelacionando las distintas fases. Esta orientación reflexiva de la escritura insiste en la revisión y la reescritura permanente de lo que se va escribiendo, hasta llegar al texto final:

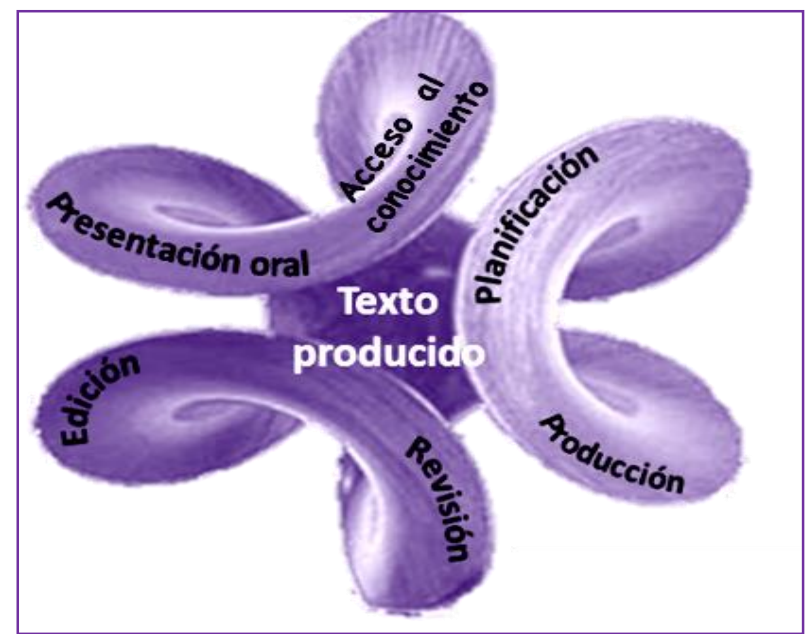

Fig.7. Dimensión: Estrategias cognitivas y metacognitivas 
En síntesis, el Grupo Didactext amplía las fases de la escritura de cuatro -acceso al conocimiento, planificación, textualización y revisión- a seis: acceso al conocimiento, planificación, textualización, revisión, edición y presentación oral. A continuación se describen brevemente las fases o etapas que articulan las estrategias cognitivas y metacognitivas del proceso de escritura: Acceso al conocimiento. Todo acto de escritura es motivado, es decir, el productor debe querer escribir algo. Esa motivación puede ser externa o interna y en cualquiera de los casos exige el planteamiento del ejercicio de escritura o estrategia de organización guiada por la formulación de un objetivo final que orienta el proceso y busca una estructura, un buen hilo conductor, que dote de significado propio al texto; en otros términos, que cumpla con el objetivo comunicativo. Para posibilitar el acto específico de composición es necesario disponer de conocimientos previos en la memoria y, en el caso de los textos académicos, recurrir a fuentes documentales de diverso tipo para ampliar esos conocimientos e integrarlos en el texto que se va a escribir.

La fase de acceso al conocimiento, desde esta perspectiva, consiste en una serie de estrategias cognitivas y metacognitivas que tienen como objetivo realizar dos actividades clave de la escritura académica: por una parte, se familiariza con el género discursivo académico, de acuerdo con el cual va a escribir (reseña, artículo de investigación, informe de laboratorio, comentario de texto, etc.) y, por otra, investiga en fuentes confiables, la información necesaria para escribir el texto. Respecto de lo primero, la familiarización implica leer ejemplares del género discursivo que va a escribir para identificar sus características relativamente estables (Bajtin, 1979; Bronckart, 1996) y, por otra, investigar para integrar en su propio escrito, información procedente de diversas fuentes.

Planificación. En esta segunda fase, también recurrente, se destacan, al menos, dos momentos. En el primero, el productor define el tema sobre el cual se va a escribir, así como la intención comunicativa del texto, lo que implica elegir un tipo de texto (argumentativo, expositivo-explicativo, descriptivo o narrativo). Además de ello, quien escribe necesita definir el género discursivo que pretende producir y esto, a su vez, implica identificar el público al que va dirigido, porque, como plantea Bajtín, este se configura dentro de un grupo socialmente constituido con características discursivas específicas que lo diferencian de otras comunidades discursivas.

En el segundo momento, el escritor organiza la información recuperada sobre el tema de escritura y planifica su aparición en el texto, esto es, piensa en la distribución de la información de acuerdo con la estructura del género discursivo. Así pues, el escritor accede al conocimiento no porque considere que estos contenidos semánticos, en algún momento, puedan derivar en producción textual, sino porque, una vez planificada la escritura del texto, se estimula el acceso al conocimiento que precisa para lograr su objetivo; dicho en otros términos, después de toda etapa de planificación sucede otra de acceso al conocimiento, entendida esta como la activación mental que posibilita la estimulación del conocimiento. 
Un aspecto que resulta fundamental es el hecho de que toda organización de la información implica la construcción de géneros discursivos. En otras palabras, en el segundo momento de la planificación se organiza la información y, como resultado de ella, según plantea el modelo, pueden aparecer estrategias de aprendizaje, tales como esquemas, fichas, mapas mentales. Estas maneras de organizar la información corresponden, indudablemente, a estrategias necesarias en la construcción del texto. Lo anterior quiere decir que, dentro del proceso de escritura general, coexisten tantos ciclos del modelo como géneros discursivos alternos se produzcan. Así, justamente, se plantea la recursividad del modelo.

Redacción. Esta fase deberá entenderse como aquella en la que el escritor produce uno o más géneros discursivos. Por esta razón, podría pensarse en, al menos, dos fases. La primera, enmarcada en la recursividad del modelo, corresponde a la producción de los géneros que tienen como propósito ordenar la información recolectada sobre el tema de escritura. La segunda corresponde a la redacción del primer borrador del género objeto de escritura y atiende tanto a las normas de organización textual interna de orden semántico, como externa, de orden estructural. Sin embargo, recordemos que los requisitos que suponen la realización de estas normas no necesariamente están expuestos de forma lineal y secuencial; puede darse la interacción entre dichas normas a medida que transcurra el proceso. Es más, esa interrelación puede favorecer de manera significativa la producción. Esta fase está directamente regida por las normas de textualidad y por los aspectos textuales que teóricos como De Beaugrande (1980), van Dijk (1980), Bronckart (1985, 1994 y 1996), De Beaugrande y Dressler (1997), Cassany (1999), Didactext (2003, 2005, 2006a, 2006b, 2007), Álvarez (2005 y 2010), Camargo, Uribe y Caro (2011) y otros, proponen para la producción del nuevo texto.

Revisión y reescritura de un texto. En esta fase se identifican las discrepancias entre el texto que se está produciendo y el que se pretende producir, lo cual implica: (i) definir qué se entiende por texto de calidad; (ii) precisar cuáles son los indicadores textuales que ponen de manifiesto que un texto es de mayor calidad que otro (indicadores textuales de calidad, ITC); y (iii) establecer qué operaciones mentales se activan y sobré qué unidades lingüísticas y textuales se interviene. Dichas operaciones y unidades pueden afectar o no el significado y pueden ser de mayor o menor entidad.

Respecto de (i), el Grupo Didactext concibe que un texto académico de calidad sea aquel que es rico informativamente, refiere fuentes necesarias y precisas, es coherente en la progresión lógica del tema, está bien cohesionado, y es correcto y adecuado al propósito que persigue. En cuanto a (ii), postula que los indicadores textuales de calidad (ITC) (ver anexo) son marcas o rasgos que otorgan a los textos corrección, concisión y propiedad, tanto en el proceso de composición como en la revisión o corrección del producto final, entendida esta última de manera recursiva. Esto significa que, cuando se revisa, habitualmente se vuelve a planificar y a reescribir, y así sucesivamente, hasta dar el texto por finalizado. A propósito de (iii), las principales 
operaciones mentales que se ponen en funcionamiento para revisar un texto son: adición, supresión, sustitución y reorganización. Las unidades lingüísticas y textuales sobre las que se interviene son: paratexto, texto, párrafo, frase, palabra, sílaba, y letra. Operaciones mentales y unidades lingüísticas se pueden combinar en el proceso de revisión, de manera que se corrijan errores y a la vez se transforme el contenido (Allal, Chanquoy and Largy, 2004; Horning and Becker, 2006; Álvarez, 2011).

Por todo ello, el Grupo Didactext concibe la revisión y la reescritura como el momento especialmente reflexivo que hace la redacción compleja, tanto en las aulas como fuera de ellas. Asimismo, la fase de revisión estará presente en cada momento de producción implicado en el proceso de escritura. Esta fase desarrolla los pasos evaluativos requeridos hasta la consolidación del texto final. Los principales fenómenos que intervienen en la revisión de la escritura tienen que ver con la función evaluadora de la lectura. Consiste en identificar los problemas del texto producido en relación con las normas de textualidad y sus principios regulativos y los demás aspectos textuales que deben tenerse en cuenta para la evaluación de los textos ya producidos. La tarea principal será el análisis de los textos intermedios o borradores y el resultado final, el texto producido.

Edición. Esta fase constituye el espacio en el cual se examina el texto, se dan los cuidados finales en relación con las ilustraciones, la dimensión notacional y su correspondencia con las normas editoriales.

Presentación oral. Esta fase corresponde al momento en el que se establece una relación directa con el auditorio, mediante la cual se hace explícito el logro durante el proceso de escritura. Aquí se recomienda la elaboración de power point o cualquier otra forma audiovisual con esquemas, videos, mapas mentales que sirvan como recursos nemotécnicos al orador, además de un dominio del lenguaje oral formal.

Todas las estrategias cognitivas (buscar información, identificar destinatario, definir intención, seleccionar y organizar información, modular según información lingüístico-textual, redactar según características pragmático-textuales, identificar problemas, reformular escritura, adecuar gráficamente el texto, preparar presentación oral, dominar habilidades orales) y las metacognitivas (establecer metas del diseño, realizar y supervisar el plan) suponen un alto grado de reflexión; en ello reside precisamente la complejidad de esta habilidad lingüística; y, por tal motivo, hablamos de escritura reflexiva.

\section{Competencia comunicativa}

En el centro del diagrama se introduce el concepto de competencia comunicativa. La presencia y estímulo de los elementos considerados en los tres círculos anteriores permite desarrollar la competencia comunicativa del sujeto; es decir, según Hymes (1972), el conjunto de sistemas subyacentes de conocimientos y habilidades necesarios para la comunicación actualizada, o, según Gumperz (1972), lo que un sujeto 
necesita saber para comunicarse eficazmente en contextos culturalmente significantes. La competencia comunicativa consta, a su vez, de diversas subcompetencias que toda persona utiliza para desarrollar y ejercer su capacidad comunicativa. Estas son: discursiva o textual, gramatical, sociolingüística, referencial o enciclopédica, literaria, sociocultural, de aprendizaje:

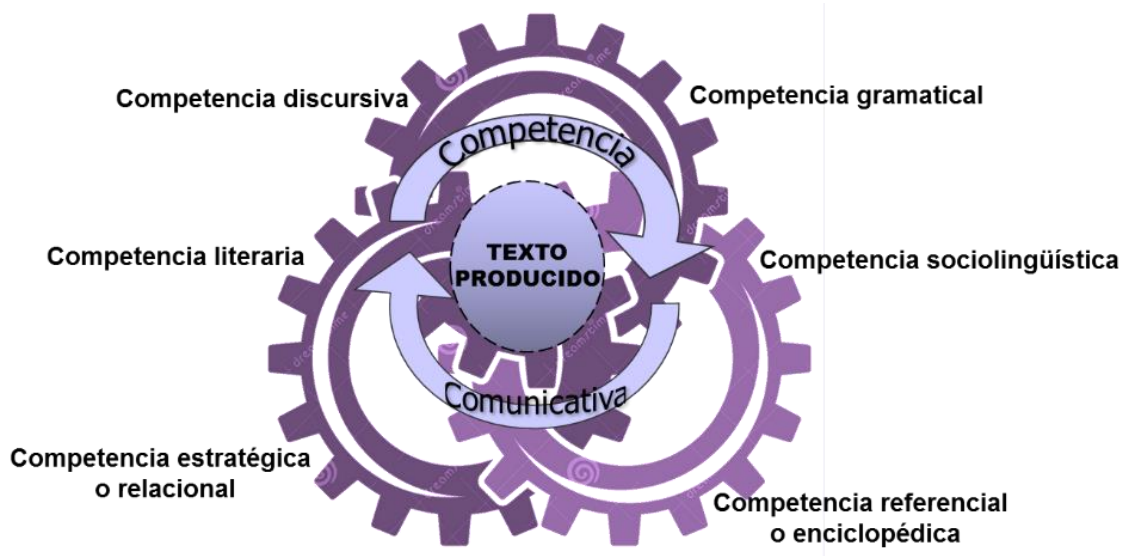

Fig. 8. Competencia comunicativa

En la Figura 9 se representa la totalidad del modelo Didactext.

\section{Creatividad}

Por último nos referiremos a la creatividad, proceso que, como ha quedado representado en el diagrama circular, parte del entorno cultural y atraviesa todas las dimensiones hasta llegar al texto producido. Algunos teóricos consideran la creatividad como un proceso especial o cualitativamente distinto de los implicados en el razonamiento común (saltos inconscientes del pensamiento, creación de nuevos paradigmas). Para Csikszeutmihalyi (1998), por ejemplo, la creatividad es cualquier acto, idea o producto que cambia o transforma un campo ya existente en uno nuevo. Para Perkins (1981) y Sternberg y Spear-Swerling (1996), no es algo en absoluto especial, es decir, la creatividad está conceptualizada dentro de los procesos relacionados con el razonamiento común. Sternberg, sin embargo, encuentra diferencias entre la creatividad y los procesos cognitivos habituales por las circunstancias que concurren en su aplicación. Nosotros nos acogemos a la noción de creatividad sustentada en el modelo triádico de Sternberg (1996), en el cual la creatividad implica los mismos procesos de codificación, comparación y combinación selectiva que se utilizan en otro tipo de razonamientos, pero que en el pensamiento creativo representan una forma novedosa (no rutinaria). 


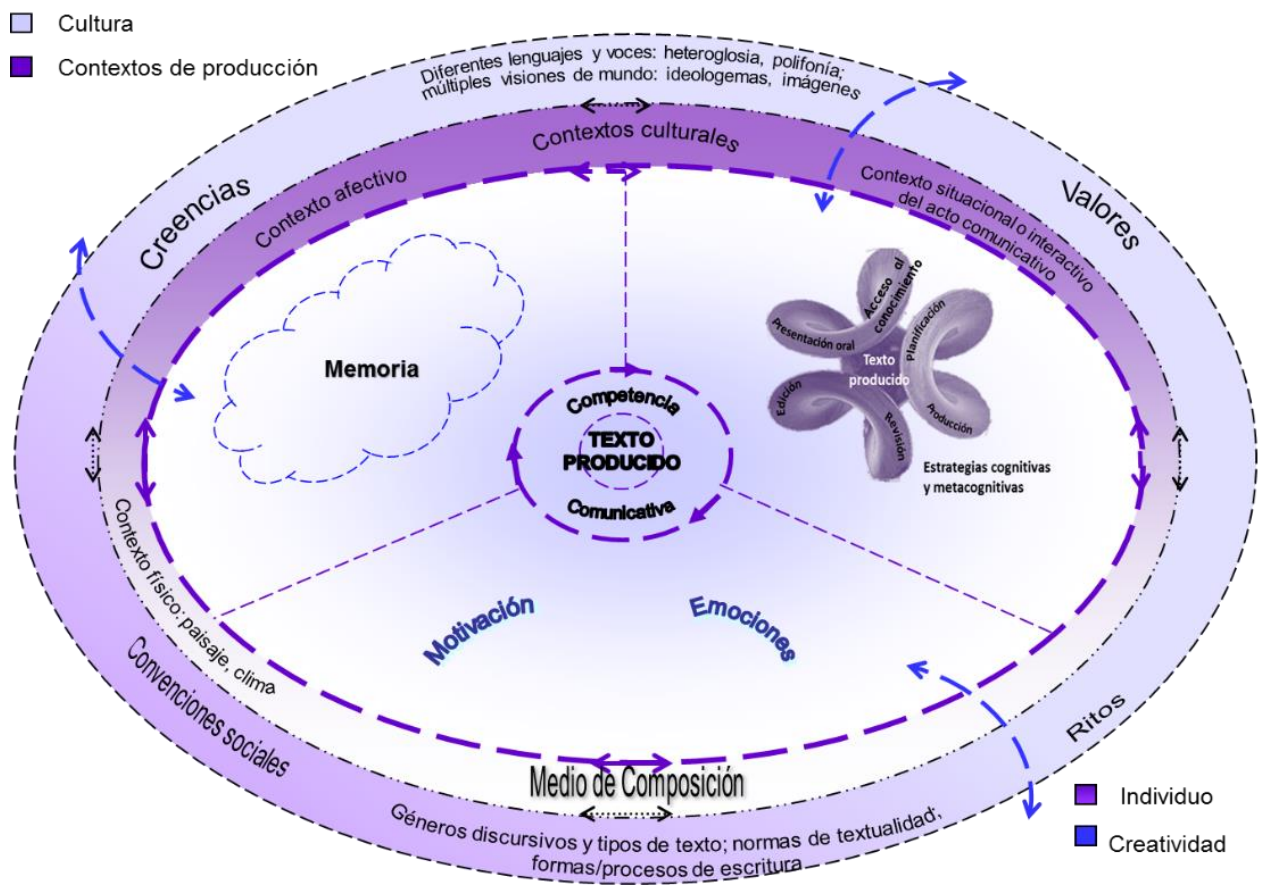

Fig. 9. Modelo sociocognitivo, pragmalingüístico y didáctico para la producción escrita

La codificación selectiva se emplea, según Sternberg, para discernir entre la información relevante e irrelevante en un problema que se va a analizar; la combinación selectiva se usa para decidir la forma como se va a unir la información relevante, y la comparación selectiva se utiliza para relacionar la información nueva con la antigua. Estos son tres procesos cognitivos separables pero relacionados.

Las personas no nacen siendo creativas; la creatividad se puede desarrollar a través de algunas etapas básicas que proponen Sternberg y Lubart (1997): redefinir los problemas; buscar lo que otros no ven; aprender a distinguir las ideas novedosas de las que no lo son; intentar realizar contribuciones innovadoras en el ámbito profesional y de trabajo; perseverar ante los obstáculos, asumir riesgos y querer crecer; descubrir y ahondar en las propias motivaciones; encontrar los entornos que recompensen el trabajo creativo.

\section{HACIA UN MODELO DIDÁCTICO DE LA ESCRITURA}

En el marco y el funcionamiento de nuestra teoría de la escritura, la orientación didáctica del modelo Didactext otorga una importancia relevante a los aspectos relacionados con cómo se aprende y cómo se ha de enseñar a escribir textos académicos o escolares en contextos de educación. La escritura es una herramienta que funciona como mediadora de la actividad social y mental (Vigotsky, 1932/1987; Graves, 1983; 
Schneuwly, 1988, 1992; Wray y Lewis, 1997; Bazerman, 2005; Castelló, 2007), y, por ello, también de las enseñanzas y de los aprendizajes (Reuter, 1996; Milian y Camps, 2000; Miras, 2000; Tolchinsky y Simó, 2001; Halté, Petitjean y Plane, 2002; Alvarado, 2003; Camps, 2003; Anguita, 2004; Carlino, 2006; Didactext, 2006a, 2006b; Reuter, 2007; Ramírez, 2010; García Parejo, 2011; Rose y Martin, 2012; Russel, 2012; Álvarez, 2013; Dolz, Gagnon, Sánchez y Mosquera, 2013). De este modo, se favorece el desarrollo mental del alumno-aprendiz, mediante las interacciones sociales mediadas lingüísticamente. Por su parte, Camargo, Uribe y Caro (2011, 211215) clasifican el modelo Didactext dentro de los modelos lingüístico-didácticos.

El conocimiento de los géneros discursivos, de las normas de textualidad y de las regularidades lingüísticas y textuales de cada uno, así como el análisis y el diseño de materiales de enseñanza y las cuestiones metodológicas en las aulas, son parte importante de la formación del profesorado, a la vez que constituyen intereses de investigación en didáctica de la escritura.

\section{CONCLUSIONES}

Concluimos la explicación de nuestra propuesta de reforma del modelo Didactext, insistiendo en la importancia de mostrar la recursividad de las fases o etapas de escritura que explicita el modelo, mediado por las formas de organización de los distintos géneros discursivos que se utilizan para este propósito. De igual modo, la construcción de estos géneros implica nuevos ciclos en los que el acceso al conocimiento, la producción y la revisión son constantes. En algunos casos, debido a las exigencias o demandas académicas, es necesario recurrir a la edición y la presentación oral. Finalmente, el texto producido es resultado de la influencia de todas y cada una de las dimensiones presentadas y de cómo este, a su vez, influye en aquellas.

Desde la publicación del Modelo en 2003, numerosos trabajos de investigación sobre el texto escrito en las aulas se han basado en la concepción de la escritura que propone Didactext y han obtenido resultados exitosos en todos los niveles de la enseñanza, desde Infantil hasta la Universidad. Por ello, podemos afirmar que su aplicación en las propuestas didácticas permite facilitar el aprendizaje, la interiorización y el automatismo de esta habilidad social.

El Modelo también ha sido utilizado en la elaboración de una plataforma on line dirigida a la formación del profesorado (Redactext 2.0) y los resultados de su utilización son exitosos y están siendo reelaborados para la enseñanza Secundaria y los estudios a Distancia.

Reafirmamos, así, la importancia de basar la actividad didáctica en las aulas en una teoría o modelo de escritura que justifique la toma de decisiones, las acciones didácticas, el diseño de materiales, el conocimiento de los géneros discursivos académicos o escolares, y la necesaria formación inicial y permanente del profesorado.

Postulamos, asimismo, la necesidad de determinar las etapas o fases de un fenómeno complejo, como la escritura, mediante la explicitación del proceso que se sigue 
al escribir, de modo que se favorezca la reflexión, la interiorización y la automatización de la capacidad de escribir. De ahí que hablemos del acceso al conocimiento, de la planificación, de la redacción propiamente dicha, de la revisión y reescritura, de la edición, y de la presentación oral.

Defendemos, así, la necesidad de contar con una teoría o modelo de la escritura que sustente la complejidad que encierra la competencia de escribir, tanto en la formación académica o escolar, como en el diseño de materiales o herramientas que faciliten el desarrollo de esta habilidad. De igual modo, juzgamos importante facilitar la tarea de evaluar, revisar y corregir la calidad de los textos. Para ello establecemos una serie de indicadores textuales que contribuyen a justificar la calidad de un texto, así como a precisar qué elementos son mejorables en su producción.

Confiamos, finalmente, en que las modificaciones que aportamos en esta reformulación del modelo Didactext contribuyan a que se escriba más y mejor, así como a continuar investigando en la enseñanza y el aprendizaje de la escritura académica en contextos escolares y académicos.

\section{BIBLIOGRAFÍA}

ADAM, J-M (1992). Les Textes: Types Et Prototypes. Paris: Nathan.

Agosto, S. (2012). El uso del periódico para la enseñanza y el aprendizaje de la escritura de textos argumentativos en cuarto curso de la enseñanza secundaria obligatoria. Tesis doctoral. Madrid: Universidad Complutense.

Agosto, S. (2013). "El Servicio de Escritura Académica, un recurso para enseñar a escribir a los futuros profesionales". Actas del XVIII Congreso Internacional de Hispanistas. Servicios de publicaciones de la Universidad de Buenos Aires.

Agosto, S. y Picó, R. (2007). "La integración de conocimientos lingüísticos para mejorar la competencia escrita en escolares de educación primaria". Filología. Universidad de Buenos Aires, XXXVIII-XXXIX: 201-222.

Aguilar, T. y GONZÁLEZ LANDA, C. (2003). "Un saber apropiado para participar" (1-108). En Aguilar, T. y CABAllero, A. (Coords.) Campos de juego de la ciudadanía. Ed. Viejo Topo.

AlBALADEJO, T. (1987). "Componente pragmático, componente de representación y modelo lingüístico-textual” (179-228). En BERNÁRDEZ, E. (comp.), Lingüística del texto. Madrid: Arco/Libros.

Allal, L. Chanquoy, L. y LARgy, P. (Eds.) (2004). Revision. Cognitive and Instructional Processes. Massachusetts: Kluwer Academic Publishers.

Alvarado, M. y Silvestri, A. (coords.) (Monografía) (2003). La composición escrita: procesos y enseñanza, Cultura y Educación. 15 (1).

Álvarez, T. (2005). Didáctica del texto en la formación del profesorado. Madrid: Síntesis.

Álvarez, T. (2010). Competencias básicas en escritura. Barcelona: Octaedro.

Álvarez, T. (2011). Revisar y reescribir textos académicos en la formación del profesorado. Revista Complutense de Educación, 21 (2): 269-294. 
Álvarez, T. (2013). Didáctica de la lengua para la formación de maestros. Barcelona: Octaedro.

Álvarez, T. y GONZÁLEZ, M. A. (2012). RedactText, guía on line para ayudar a redactar. Relada. Revista Electrónica de ADA-Madrid (Aula a Distancia Abierta de la Comunidad de Madrid. http://www.upm.es/adamadrid).

Álvarez, T. y RAMíREZ, R. (2006). "Teorías o modelos de producción de textos en la enseñanza y el aprendizaje de la escritura". Didáctica (Lengua y Literatura), Universidad Complutense, 18: 29-60.

AMABILE, T. M. (1988). "A model of creativity and innovation in organizations". Research in Organizational Behavior, 10: 123-167.

ANDERSON, J. y ANDERSON, J. R. (1982). The Architecture of Cognition. Cambridge, M.A, Harvard University Press.

ANDERSON, J. y ANDERSON, J. R. (2001). Aprendizaje y memoria. Un enfoque integral, México: Mc Graw Hill.

ANDUEZA, A. (2011). Escribir para promover el aprendizaje significativo y la competencia discursiva en la asignatura de "Estudio y comprensión de la naturaleza” en octavo año básico. Tesis doctoral. Madrid: Universidad Complutense.

BAJTIN, M. (1979). Estética de la creación verbal. México: Siglo XXI, 1982.

BAJTIN, M. (1989). Teoría y estética de la novela. Trad. H. KRIUKOVA y V. CAZCARRA. Madrid: Taurus.

BandurA, A. (1987). Pensamiento y acción. Fundamentos sociales. Barcelona: Martínez Roca.

BAZERMAN, Ch. et al. (2005). Reference Guide to Writing Across the Curriculum. Indiana: Parlor Press.

BAZERMAN, Ch. (2009). "Genre and cognitive development". In BAZERMAN, Ch., Bonini, A. y FigueIREDO, D. (Eds.). Genre in a Changing World (279-294). Indiana: Parlor Press and WAC Clearinghouse.

BAZERMAN, Ch. et al. (Eds.) (2010). Traditions of Writing Research. New York: Routledge.

Beaugrande, R. de (1980). Text Discourse, and Process: Toward a Multidisciplinary Science of Text. Norwood, New Jersey: Ablex.

BEAUGRANDE, R. De y DRESSLER, W. (1997). Introducción a la lingüística del texto. Trad. Bonilla, S. Barcelona: Ariel.

BEREITER, C. y SCARDAMALIA, M. (1977). The Psychology of Written Composition. Hillsdale, New Jersey: Erlbaum.

BLOCH, H. et al. (1992).Gran diccionario de psicología. Ediciones del Prado, 1996.

BRONCKART, J. P. (1985). Las ciencias del lenguaje: ¿un desafío para la enseñanza? París: UNESCO.

BRONCKART, J. P. (1994). Le fonctionnement des discours: Un modèle psychologique et une méthode d'analyse. Lausanne: Delachaux et Niestlé.

Bronckart, J. P. (1996). Activité langagière, textes et discours. Pour un interactionisme socio-discursif. Lausanne, Delachaux et Niestlé. 
BRUNER, J. (1984). Acción, pensamiento y lenguaje. Madrid: Alianza.

BRUNER, J. (2001). El proceso mental en el aprendizaje. Madrid: Narcea.

CAMARGO, Z. y URIBE, G. (2007). "Modelos de comprensión y producción textual y sus posibilidades de proyección didáctica". Cuadernos Interdisciplinarios pedagógicos, 8: 25-67. Armenia: Universidad del Quindío, Colombia.

CAMARGO, Z. y URIBE, G. (2014). "Estado del arte de la investigación en escritura académica en la universidad colombiana". Comunicación en Seminario Iberoamericano sobre Investigación en Escritura Académica. Facultad de Educación Centro de formación del profesorado. Universidad Complutense de Madrid.

CAmargo, Z., Uribe, G., y CARO, M. A. (comp.). (2003). Secuencias didácticas para aprender a escribir. Barcelona: Graó.

CAmargo, Z., Uribe, G., y CARO, M. A. (2011). Didáctica de la comprensión y producción de textos académicos. ( $2^{\mathrm{a}}$ ed.). Armenia: Universidad del Quindío, Colombia.

CARDONA, D. (2014). Aplicación del modelo investigativo propuesto por el Grupo Didactext para el desarrollo de los procesos de escritura de textos expositivoexplicativos, con los estudiantes de grado $6^{\circ}$ de Educación Básica. Trabajo de fin de Máster. Maestría en Ciencias de la Educación. Universidad del Quindío. Colombia.

CARLINO, P. (2006). Escribir, leer y aprender en la universidad. Una introducción a la alfabetización Académica. Buenos Aires: Fondo de Cultura Económica.

CASSANY, D. (1999). Construir la escritura. Barcelona: Paidós.

CASTElló, M. (Coord.) (2007). Escribir y comunicarse en contextos científicos y académicos. Conocimientos y estrategias. Barcelona: Graó.

Chevallard, Y. (1991). La transposition didactique. Grenoble: La Pensée Sauvage. COLE (1999). Psicología cultural. Una disciplina del pasado y del futuro. Trad. T. DEL AMO. Madrid: Morata.

CsikszeutMihalyi, M. (1998). Creatividad. Trad. J. Tosaus AbADÍA. Barcelona: Paidós.

DELGADO, S. (2014). "La escritura de reflexiones pedagógicas en el marco de una intervención didáctica para optimizar la enseñanza de la escritura de textos argumentativos por parte de docentes de básica primaria". Seminario Iberoamericano sobre Investigación en Escritura Académica. Facultad de Educación - Centro de formación del profesorado. Universidad Complutense de Madrid.

DIDACTEXT, Grupo (2003). "Modelo sociocognitivo, pragmalingüístico y didáctco para la producción de textos escritos". Didáctica (Lengua y Literatura), 15: 75102.

DIDACTEXT, Grupo (2005). Los procesos de escritura y el texto expositivo en la mejora de la competencia escrita de los escolares de Educación Primaria. Madrid: Editorial Complutense.

DiDACTEXT, Grupo (2006a). "La escritura de textos expositivos en aulas de 
primaria”. A. Camps (ed.). Diálogo e investigación en las aulas: 99-118. Barcelona: Graó.

DIDACTEXT, Grupo (2006b). "Secuencia didáctica para la escritura de textos expositivos". Textos de Didáctica de la Lengua y de la Literatura, 43: 97-106. Barcelona: Graó.

DIDACTEXT, Grupo (2007). Los procesos de escritura y el texto expositivo en la mejora de la competencia escrita de los escolares de sexto de educación primaria. Madrid: Universidad Complutense. Línea 300.

DIJK, T. van (1980).Estructuras y funciones del discurso. México: Siglo XXI, 1983.

DiJK, T. van (1983). La ciencia del texto. Un enfoque interdisciplinario. Trad. S. HUNZINGER. Barcelona: Paidós, 1994.

DiJK, T. van (1997a). El discurso como estructura y proceso. (2000a). Barcelona: Gedisa.

DIJK, T. van (1997b). El discurso como interacción social. (2000b). Barcelona: Gedisa.

DIJK, T. van (2003): Ideología y discurso. Ariel: Barcelona.

DILEMA, Grupo (2006-2007). Estrategias para la comprensión y producción de textos expositivo-explicativos desde un enfoque sociocultural. Una propuesta didáctica dirigida a profesores de cuarto y quinto grado de educación básica para el mejoramiento de la competencia lectoescritural de sus estudiantes. Vicerrectoría de Investigaciones de la Universidad del Quindío, Colombia.

DILEMA, Semillero (2006). Enseñanza y aprendizaje de los textos funcionales para la mejora de la producción escrita de los estudiantes de cuarto y quinto grado de la Institución Educativa Santa Teresa de Jesús. Armenia, Colombia.

Dolz, J., Noverraz, M. y SChNeuwly, B. (2001). S' exprimer en français: séquences didactiques pour l'oral et pour l'écrit, IV, (13n séquences didactiques $7 e-8 e-9 e)$. Bruxelles: De Boeck.

Dolz, J., Gagnon, R., SANCheZ, V. y MosQuera, S. (2013). Producción escrita y dificultades de aprendizaje. Barcelona: Graó.

FitTs, P. (1964). "Perceptual-Motor Skill Learning" (242-285). En Melton, A. (Ed.), Categories of Human Learning. New York: Academy Press.

FLAVEL, J. H. (1979). "Metacognitive aspect of problem solving" (231-236). En RESNICK, L. (ed.). The Nature of Intelligence. Hillsdale, N. J.: Lawrence Erlbaum.

GARCíA, I. (coord.). (2011). Escribir textos expositivos en el aula. Fundamentación teórica y secuencias didácticas para diferentes niveles de enseñanza. Barcelona: Graó.

GASKINS, I. y ELLIOT, T. (1999). Cómo enseñar estrategias cognitivas en la escuela. El manual Benckmark para docentes. Trad. PIÑA, C. Barcelona: Paidós. 
GIRALDO, D. (2014). "La producción de textos argumentativos publicitarios en un proyecto ambiental educativo. Una propuesta dirigida a estudiantes del Programa de Formación Complementario de la Escuela Normal Superior del Quindío". Comunicación en Seminario Iberoamericano sobre Investigación en Escritura Académica. Facultad de Educación. Universidad Complutense de Madrid.

GonZÁlez Landa, C. y Aguilar, T. (2003). "Saber”, en: A.A.V.V, Ciudadanía. El Viejo Topo. Madrid.

Graves, D.H. (1983). Didáctica de la escritura. (1991). Madrid: Morata/MEC.

GuMPERZ, J. J. (1972). "Preface" y "Introduction". En GUMPERZ, J. J. y HYMES, D. (Comps.). Directions in Sociolinguistics. New York: Holt, Rinehart \& Winston. HABERMAS, J. (1980): Teoría de la acción comunicativa I, Madrid, Taurus. (1992). HALliDAY, M.A.K. y MARTIN, J. R. (1993). Writing Science literacy and Discourse Power. London: The Palmer Press.

Halté, J. F., Petitjean, A. y Plane, S. (2002). L'écriture et son apprentissage. Pratiques, 115-116. Université de Metz.

HARRE, R. y LAMB, R. (dirs) (1986). Diccionario de Psicología evolutiva y de la educación. Barcelona: Paidós, 1990.

HAYES, J. (1996). "A new framework for understanding cognition and affect in writing” (1-27). En LEVY, C. M. y RANSDELL, S. (eds.). The science of writing: Theories, Methods, Individual Differences, and Applications. New Jersey: Lawrence Erlbaum Associates.

HAYES, J. y FLOWER, L. (1980). "Identifying the organization of writing process" (330). En GregG, L. W. y Steinberg E. (eds.). Cognitive Processes in Writing. Hillsdale, N. J. Lawrence, Erlbaum.

HAYES, J. y GRADWOHL, J. (1996). "On the nature of planning in writing" (29-55). En LEVY, M. et al. (eds.). The Science of Writing. New Jersey: Lawrence Erlbaum Associates.

HERNÁNDEZ, A. y QUINTERO, A. (2001). Comprensión y composición escrita. Estrategias de aprendizaje. Madrid: Síntesis.

Horning, A. and BeCKer, A. (eds.) (2006). Revision. History, Theory, and Practice. Indiana: Parlor Press.

HYMES, D. H. (1972). "Models of the interaction of language and social life". (3571). En GuMPERZ, J. y HyMeS, D. H. (Eds.) Directions in Sociolinguistics. The Ethnography of Communication. New York: Basil Blackwell.

ISENBERG, H. (1983). "Cuestiones fundamentales de tipología textual". En BERNÁRDEZ, E. (comp.). Lingüística del texto, Madrid, Arco/Libros, 1987.

JustiCiA, F. et al. (2000). Programas de intervención cognitiva. Granada: Grupo editorial universitario.

KINTSCH, W. (1998). Comprehension. A paradigm for cognition, Cambridge: University Press.

KristeVA, J. (1978). Semiótica. Madrid: Fundamentos.

LAVE, J. y Wenger, E. (1991). Situated Learning. Cambridge: University Press. 
LEÓN, K. (2014). Laboratorio didáctico para la producción textual administrativa. Una propuesta dirigida a los aprendices del SENA, Regional Quindio. Trabajo de fin de Máster. Maestría en Ciencias de la Educación. Universidad del Quindío, Colombia.

LOTMAN, J. y EsCUELA DE TARTU (1979). Semiótica de la cultura. Madrid: Cátedra. MARTíNEZ, L. (2014). "La escritura de bitácoras como estrategia evaluativa para la argumentación oral en el aula con estudiantes de 8 grado de la Institución Educativa Cristóbal Colón de Armenia”. Seminario Iberoamericano sobre Investigación en Escritura Académica. Facultad de Educación - Centro de formación del profesorado. Universidad Complutense de Madrid.

MAYOR, J., SUENGAS, A. y GONZÁLEZ, J. (1995). Estrategias metacognitivas. Aprender a aprender y aprender a pensar. Madrid: Síntesis.

MENDOZA, A. (coord) (1998). Conceptos clave en didáctica de la lengua y la literatura. Sociedad Española de Didáctica de la Lengua y la Literatura/Horsory, ICE de la Universidad de Barcelona.

MILIAN, M. y CAMPS, A. (comp.) (2000). El papel de la actividad metalingüística en el aprendizaje de la escritura. Buenos Aires: Homo Sapiens.

MiLLER, G. (1956). "The magical number seven plus or minus two. Some limits on our capacity for processing information". Psychological Review, 63: 81-97.

MirAS, M. (2000). "La escritura reflexiva. Aprender a escribir y aprender acerca de lo que se escribe". Infancia y Aprendizaje, 89: 65-80.

MONEREO, C. (1990). "Las estrategias de aprendizaje en la educación formal: enseñar a pensar y sobre el pensar". Infancia y aprendizaje, 50: 25.

MONTES, L. N. (2014). La enseñanza y el aprendizaje de estrategias cognitivas y metacognitivas para la producción de textos expositivos y narrativos. Reflexiones teóricas y propuesta didáctica dirigida a niños de $5^{\circ}$ de básica primaria de la Institución Educativa Sagrado Corazón de Jesús de Trujillo, Valle. Trabajo de fin de Máster. Maestría en Ciencias de la Educación. Universidad del Quindío.

NEMIROVSKY, M. (1999). Sobre la enseñanza del lenguaje escrito... y temas aledaños. Barcelona: Paidós.

PARRA, E. (2015). Cualificación de los procesos de producción de textos expositivoexplicativos: el caso del artículo de divulgación científica. Una propuesta didáctica dirigida a estudiantes de I semestre de Ingeniería de Sistemas de la Universidad del Quindío. Trabajo de fin de Máster. Maestría en Ciencias de la Educación. Universidad del Quindío, Colombia.

PERKINS, D. N. (1981). The Mind's Best Work. Cambridge: Harvard University Press.

PINILLA, D. (2013). Integración de las áreas de lenguaje, ciencias sociales y ciencias naturales en los currículos de básica primaria como perspectiva dinamizadora de procesos escritores de textos expositivo-explicativos. Trabajo de fin de Máster. Maestría en Ciencias de la Educación. Universidad del Quindío, Colombia. 
PINTRICH, P. R. (1989). "The dynamic interplay of student motivation and cognition in the college classroom" (117-160). En AMES, C. y MAHER, M. L. (eds.). Advances in motivation and achievement, 6 , Greenwich, CT: JAI Press.

Pozo, J. I. (2001). Humana mente. El mundo, la conciencia y la carne. Madrid: Morata.

Pozo, J. I. y GóMEZ, M. A. (1998). "Más allá del equipamiento cognitivo de serie: la comprensión de la naturaleza de la materia". En BENLLOCH, M. (ed.). La educación científica: más allá de la escuela. Barcelona: Paidós.

PUENTE, A. (1998). Cognición y aprendizaje. Madrid: Pirámide.

QUINTERO, D. (2014). Implementación de estrategias cognitivas y metacognitivas para mejorar el rendimiento del aprendizaje, mediante la comprensión y producción de textos expositivos. Una propuesta de intervención dirigida a los alumnos del grado $5^{\circ}$ de una Institución Educativa Rural. Trabajo de fin de Máster. Maestría en Ciencias de la Educación. Universidad del Quindío.

RAMíREZ, R. (2004). La competencia argumentativa escrita en estudiantes de sexto grado de Educación Básico. Tesis doctoral. Madrid: Universidad Complutense.

RAMíreZ, R. (2010). Didáctica de la lengua y de la argumentación escrita. Pasto (Colombia): Universidad de Nariño.

REUTER, Y. (1996). Enseigner et apprendre à écrire. Construire une didactique del'écriture. Paris: ESF.

REUTER, Y. (ed.) (2007). Dictionnaire des concepts fondamentaux des didactiques. Bruxelles: De Boeck.

Rose, D. y MARTIN, J. R. (2012). Learning to Write, Reading to Learn: Genre, Knowledge and pedagogy in the Sydney School. London: Equinox.

RUSSEL, D. (2012). "Écrits universitaires/écrits professionnalisants/ écrits professionnels: est-ce qu' 'écrire pour apprendre' est plus qu'un slogan?". Pratiques, 153-154: 21-34. Université de Metz.

SALOMON, G. (1992). "Las diversas influencias de la tecnología en el desarrollo de la mente". Infancia y aprendizaje, 58: 143-159.

Salomon, G. (dir.) (1989). Léxicos. Ciencias de la Educación. Psicología. Madrid: Santillana.

SCHNEUWLY, B. (1988). Le langage écrit chez l'enfant : la production des textes informatifs et argumentatifs. Paris: Delachaux et Niestlé.

SCHNEUWLY, B. (1992). "La concepción vygotskiana del lenguaje escrito". Comunicación, Lenguaje y Educación, 16: 49-59.

SimON, H. (1995). "The information-processing theory of mind". American Psychologist, 50: 507-508.

SOMMERS, N. (2007). "Revision strategies of student writers and experienced adult writers" (195-206). En T. JoHnson. Teaching Composition. Background Readings. Boston: Bedford/St. Martin's.

STERNBERG, R. y SPEAR-SWERLING, L. (1996). Enseñar a pensar. Trad. R. LLAVORI DE MIcheo. Madrid: Santillana. 
STERNBERG, R., SPEAR-SWERLING, L y LUBART, T. (1997). La creatividad en una cultura conformista. Trad. F. MELER. Barcelona: Paidós.

TOLCHINSKY, L. y SIMÓ, R. (2001). Escribir y leer a través del currículum. Barcelona: ICE/Horsori.

URIBE, G. (2006). La enseñanza de la composición escrita de textos expositivo-explicativos. Presupuestos teóricos y propuesta didáctica dirigida a profesores de programas no humanísticos de la Universidad del Quindio, Colombia. Tesis doctoral.

Vygotsky, L. S. (1932). Pensamiento y lenguaje. Buenos Aires: La Plèyade,1987.

WEINSTEIN, C. y MAYER, R. (1986). "The teaching of learning strategies" (315-327). En M. WiTTROCK (comp.). Handbook of Research on Teaching: New York: MacMillan.

WeRTSCH, J. (1991). Voces de la mente. Trad. A. SILVESTRI. Madrid: Visor, 1993.

Wertsch, J., Del Río, P. y Álvarez, A. (eds.) (1995). Sociocultural Models of Mind. Cambridge: University Press.

ZAMBRANO, J. D. (2014). "La argumentación científica. Propuesta didáctica para la escritura argumentativa en ciencias biológicas". Seminario Iberoamericano sobre Investigación en Escritura Académica. Facultad de Educación. Universidad Complutense de Madrid.

\section{ANEXO}

\begin{tabular}{|c|c|c|c|c|c|c|}
\hline $\mathbf{0}$ & \multicolumn{2}{|c|}{ Indicadores textuales de calidad (ITC) } & MB & B & $\mathbf{R}$ & D \\
\hline \multirow[t]{6}{*}{1} & \multicolumn{2}{|c|}{ Desarrolla un tema reconocible como hilo conductor de su texto } & & & & \\
\hline & Puntuación & $\mathbf{N}^{0}$ errores & & & & \\
\hline & MB & $\begin{array}{l}\text { Todos los subtemas están relacionados con el } \\
\text { tema }\end{array}$ & & & & \\
\hline & $\mathbf{B}$ & $\begin{array}{l}\text { Uno de los subtemas está mucho más desarro- } \\
\text { llado que los demás }\end{array}$ & & & & \\
\hline & $\mathbf{R}$ & $\begin{array}{l}\text { Dos de los subtemas están mucho más desa- } \\
\text { rrollados que los demás }\end{array}$ & & & & \\
\hline & D & $\begin{array}{l}\text { Solo desarrolla un subtema o se rompe el hilo } \\
\text { conductor por interrupción del subtema }\end{array}$ & & & & \\
\hline 2 & \multicolumn{2}{|c|}{ Se advierte correspondencia entre título y contenido } & & & & \\
\hline \multirow[t]{4}{*}{3} & \multicolumn{2}{|c|}{ Se reconoce un propósito de escritura } & & & & \\
\hline & Puntuación & $\mathbf{N}^{0}$ errores & & & & \\
\hline & MB & No introduce otro propósito distinto & & & & \\
\hline & B & $\begin{array}{l}\text { Cumple propósito, aunque introduce elemento } \\
\text { lingüístico inadecuado, como la primera per- } \\
\text { sona }\end{array}$ & & & & \\
\hline
\end{tabular}




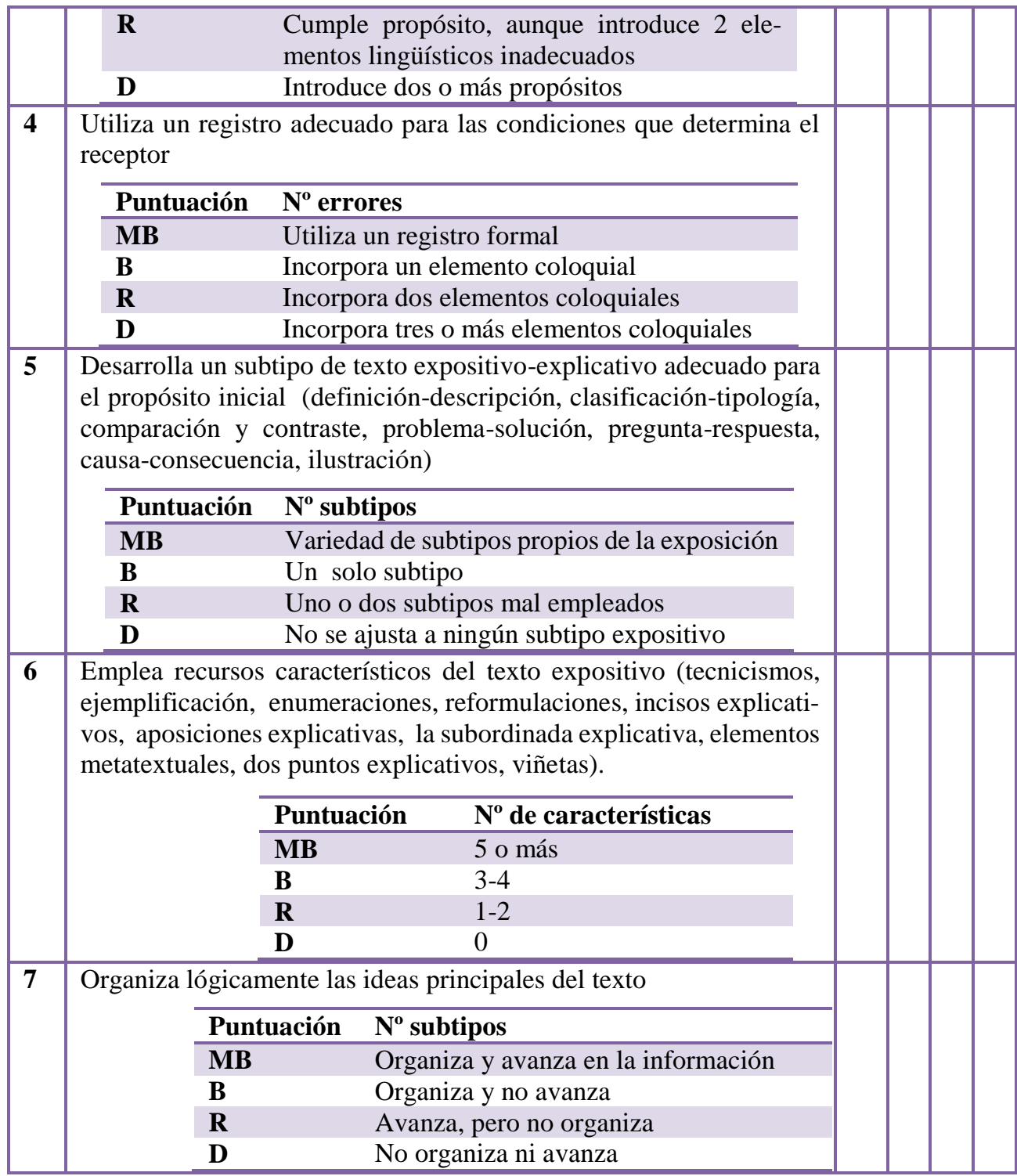




\begin{tabular}{|c|c|c|c|c|}
\hline \multirow[t]{6}{*}{8} & \multicolumn{4}{|c|}{ Presenta riqueza informativa en el desarrollo de las ideas } \\
\hline & \multicolumn{4}{|c|}{ Puntuación $\quad \mathrm{N}^{0}$ subtipos } \\
\hline & MB & \multicolumn{3}{|c|}{$\begin{array}{l}\text { Presenta riqueza informativa ajustada al } \\
\text { receptor, al tema y al propósito }\end{array}$} \\
\hline & B & \multicolumn{3}{|c|}{$\begin{array}{l}\text { Presenta riqueza informativa ajustada al } \\
\text { receptor, pero no al tema ni al propósito }\end{array}$} \\
\hline & $\mathbf{R}$ & \multicolumn{3}{|c|}{$\begin{array}{l}\text { Presenta riqueza informativa ajustada al } \\
\text { tema, pero no al receptor ni al propósito }\end{array}$} \\
\hline & D & \multicolumn{3}{|c|}{ No ajusta el nivel informativo al receptor } \\
\hline \multirow[t]{6}{*}{9} & \multicolumn{4}{|c|}{ Estructura su texto en párrafos que responden a unidades de sentido } \\
\hline & & Puntuación & \multicolumn{2}{|c|}{$\mathbf{N}^{0}$ errores } \\
\hline & & MB & \multicolumn{2}{|l|}{ Siempre } \\
\hline & & B & \multicolumn{2}{|c|}{ Frecuentemente } \\
\hline & & $\mathbf{R}$ & \multicolumn{2}{|c|}{ Raramente } \\
\hline & & D & \multicolumn{2}{|l|}{ Nunca } \\
\hline \multirow[t]{6}{*}{10} & \multicolumn{4}{|c|}{ Construye correctamente las oraciones } \\
\hline & & Puntuación & \multicolumn{2}{|c|}{$\mathbf{N}^{0}$ errores } \\
\hline & & MB & \multicolumn{2}{|l|}{0} \\
\hline & & B & \multicolumn{2}{|l|}{1} \\
\hline & & $\mathbf{R}$ & $2-3$ & \\
\hline & & D & 4 o más & \\
\hline 11 & $\begin{array}{l}\text { Usa organizadores } \\
\text { párrafos y oracion }\end{array}$ & $\begin{array}{l}\text { y conectores } \\
\text { s }\end{array}$ & extuales adecu & idos para encadenar \\
\hline & & Puntuación & Cantidad & Diversidad \\
\hline & & MB & + & + \\
\hline & & B & - & + \\
\hline & & $\mathbf{R}$ & + & - \\
\hline & & D & - & - \\
\hline 12 & Aplica al vocabula & rio empleado & riterios de var & edad y propiedad \\
\hline & & Puntuación & Propiedad & Variedad \\
\hline & & MB & + & + \\
\hline & & B & + & - \\
\hline & & $\mathbf{R}$ & - & + \\
\hline & & D & 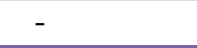 & - \\
\hline 13 & Selecciona paratex & tos que comp & ementan el con & tenido del texto \\
\hline & Puntuación & $\begin{array}{l}\text { Canti- } \\
\text { dad }\end{array}$ & Relacionados & con el texto \\
\hline & MB & + & + & \\
\hline & B & - & + & \\
\hline & $\mathbf{R}$ & $-/+$ & - & \\
\hline & D & NO HAY & & \\
\hline
\end{tabular}




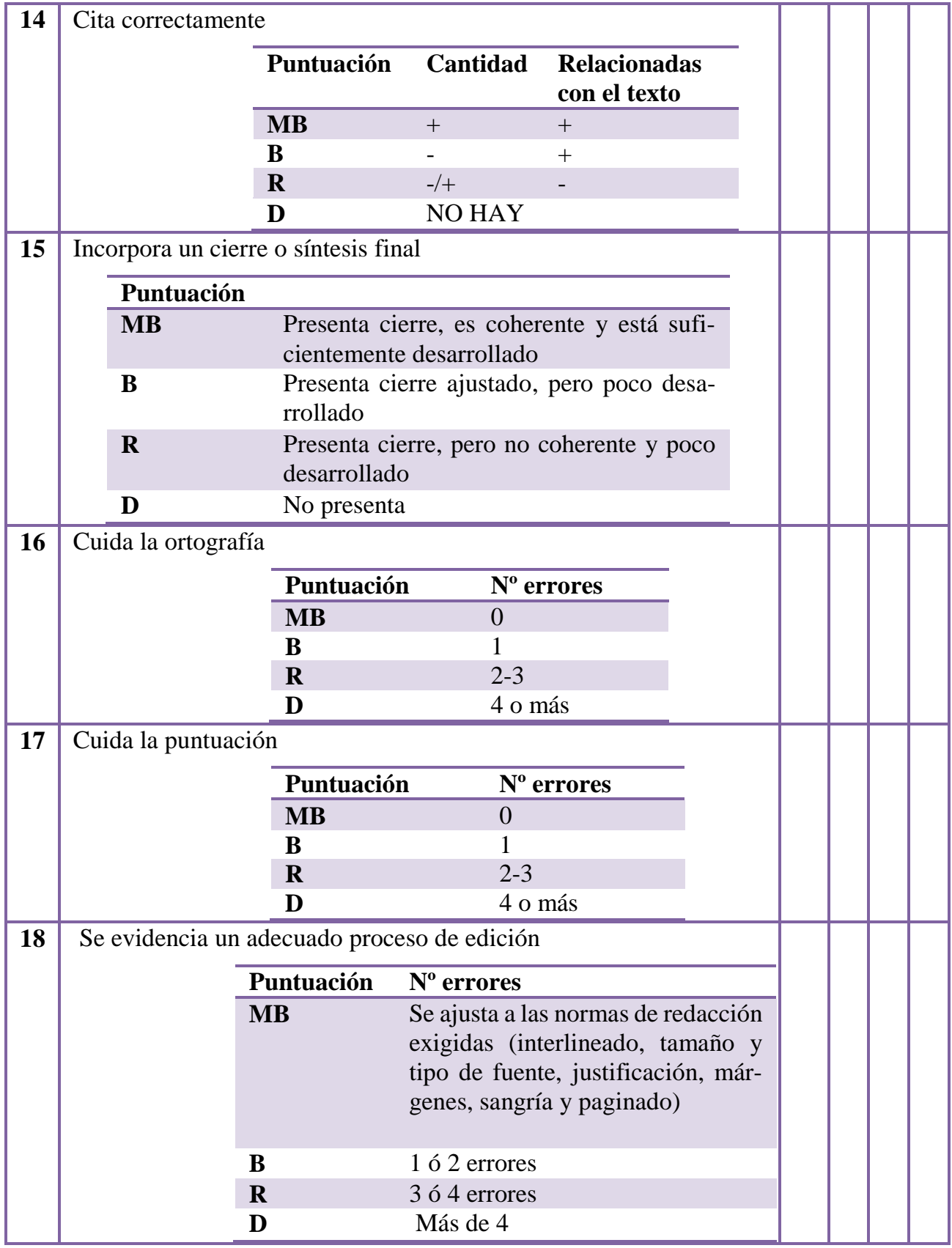

